\title{
A comprehensive meta-analysis of interpretation biases in depression
}

\author{
Jonas Everaert ${ }^{\mathrm{a}, \mathrm{b},{ }^{*}, \text { Ioana R. Podina }}{ }^{\mathrm{c}}$, and Ernst H. W. Koster ${ }^{\mathrm{b}}$ \\ a Department of Psychology, Yale University, United States of America \\ ${ }^{\mathrm{b}}$ Department of Experimental Clinical and Healthy psychology, Ghent University, Belgium \\ ${ }^{\mathrm{c}}$ Laboratory of Cognitive Clinical Sciences, Department of Psychology, University of Bucharest, \\ Romania
}

* Corresponding author:

Jonas Everaert, Yale University, Department of Psychology, 2 Hillhouse Avenue, New Haven, CT 06520, United States of America; Email: jonas.everaert@gmail.com 


\begin{abstract}
Interpretation biases have long been theorized to play a central role in depression. Yet, the strength of the empirical evidence for this bias remains a topic of debate. This meta-analysis aimed to estimate the overall effect size and to identify moderators relevant to theory and methodology. PsycINFO, Embase, Web of Science, Scopus, PubMed, and dissertation databases were searched. A random-effects meta-analysis was performed on 87 studies $(N=9,443)$. Results revealed a medium overall effect size ( $\mathrm{g}=0.72,95 \%$-CI:[0.62;0.82]). Equivalent effect sizes were observed for patients diagnosed with clinical depression ( $\mathrm{g}=0.60$, 95\%-CI:[0.37;0.75]), patients remitted from depression ( $\mathrm{g}=0.59,95 \%$-CI:[0.33;0.86]), and undiagnosed individuals reporting elevated depressive symptoms ( $\mathrm{g}=0.66,95 \%$ CI:[0.47;0.84]). The effect size was larger for self-referential stimuli (g=0.90, 95\%CI[0.78;1.01]), but was not modified by the presence $(\mathrm{g}=0.74,95 \%$ - $\mathrm{CI}[0.59 ; 0.90])$ or absence $(\mathrm{g}=0.72,95 \%-\mathrm{CI}[0.58 ; 0.85])$ of mental imagery instructions. Similar effect sizes were observed for a negative interpretation bias ( $\mathrm{g}=0.58,95 \%$-CI:[0.40;0.75]) and lack of a positive interpretation bias ( $\mathrm{g}=0.60,95 \%$-CI:[0.36;0.85]). The effect size was only significant when interpretation bias was measured directly $(\mathrm{g}=0.88,95 \%$-CI $[0.77 ; 0.99])$, but not when measured indirectly $(\mathrm{g}=0.04,95 \%-\mathrm{CI}[-0.14 ; 0.22])$. It is concluded that depression is associated with interpretation biases, but caution is necessary because methodological factors shape conclusions. Implications and recommendations for future research are outlined.
\end{abstract}

Keywords: Interpretation bias; Cognitive bias; Depression; Meta-analysis; Review. 


\section{Introduction}

Depression is one of the most common psychiatric disorders causing a severe personal and societal burden. The global point prevalence rate of depression is estimated at $4.7 \%$ and the annual incidence at 3.0\% (Ferrari et al., 2013), with about 350 million people currently suffering from this disorder worldwide (WHO, 2012). In addition to its high prevalence, depression is marked by severe symptomatic suffering, impaired social and professional functioning, substantial loss of quality of life, as well as increased risk of suicide (Kessler \& Bromet, 2013). The economic costs to society are estimated at a total of $\$ 83.1$ billion a year in medical costs, suicide-related mortality costs, and workplace costs (Greenberg, Fournier, Sisitsky, Pike, \& Kessler, 2015). These facts clearly demonstrate that depression represents a major public health concern. Efforts to identify the factors involved in the onset and maintenance of depression are therefore particularly important to better understand and treat this devastating disorder.

The past several decades have witnessed burgeoning research on cognitive factors involved in depression (Gotlib \& Joormann, 2010; Mathews \& Macleod, 2005). This line of research represents one of the most important and direct translations of cognitive science to uncover emotionally distorted cognitive processes that put people at risk to develop and/or maintain depressive symptoms. In particular, one important line of research has investigated depression-linked abnormalities in how people interpret ambiguous emotional information.

Ambiguity is commonly encountered in everyday life. Imagine, for example, a person in the audience frowning his eyebrows while you are giving a speech or imagine that you were not invited to a party while several of your friends are going. These events are ambiguous because they can be understood in multiple ways (e.g., think about how these situations may turn out for you or how others may think of you). People need to interpret such ambiguous information to make sense of what is happening to them. Interpretation is a semantic process through which people construct mental representations that resolve the ambiguity (Blanchette 
\& Richards, 2010; Hirsch, Meeten, Krahé, \& Reeder, 2016). In depression, the process of interpretation is theorized to be marked by systematic emotional biases known as interpretation biases. Specifically, cognitive theorists have hypothesized that individuals with elevated depression levels have a tendency to create more negative and fewer positive meanings to explain ambiguous information (Clark, Beck, \& Alford, 1999; Ingram, Miranda, \& Segal, 1999). Importantly, interpretation biases are typically regarded as proximal cognitive causes of depression and not as some mood-dependent correlates (Beck \& Haigh, 2014; Ingram et al., 1999). Therefore, interpretation biases are a primary target in many psychological treatments for depression (Berking, Ebert, Cuijpers, \& Hofmann, 2013; Clark et al., 1999) and cognitive training methodologies (Cristea, Kok, \& Cuijpers, 2015; Menne-Lothmann et al., 2014).

\section{Prior Reviews and Research}

The theoretical prediction that depression is linked to interpretation biases has generated a wealth of empirical scrutiny in the past four decades. Cross-sectional and longitudinal studies have employed a wide variety of interpretation bias paradigms in diverse adult populations including patients diagnosed with major depression, undiagnosed individuals with elevated self-reported depressive symptoms, and patients remitted from depression (Blanchette \& Richards, 2010; Foland-Ross \& Gotlib, 2012; Gotlib \& Joormann, 2010; Mathews \& Macleod, 2005; Wisco, 2009). Although the theoretical predictions are straightforward, the empirical data has been far less clear-cut. In interpreting the available data, some narrative reviews have concluded that a considerable number of studies have yielded evidence for interpretation biases in depression and provide substantial support for predictions by cognitive models (Mathews \& Macleod, 2005; Wisco, 2009). In contrast, other reviews have emphasized inconsistencies in research findings and pointed out that much of the evidence base is plagued by confounding factors even to the extent that there is limited direct support for the hypotheses (Blanchette \& Richards, 2010; Foland-Ross \& Gotlib, 2012; Gotlib \& Joormann, 2010). In light of these 
different opinions and recent research that has produced mixed findings (e.g., Beard, Rifkin, \& Björgvinsson, 2017; Cowden Hindash \& Rottenberg, 2015; Käse et al., 2013; Moser, Huppert, Foa, \& Simons, 2012; Normansell \& Wisco, 2016; Sears, Suzie Bisson, \& Nielsen, 2011), the strength of support for interpretation biases in depression remains a topic of scientific debate.

To date, it has yet to be quantified which factors derived from theory and research methodology contribute to the variability in research findings. Interpretation biases in depression have only been subjected to meta-analysis indirectly, as part of a meta-analysis on implicit processes in depression (Phillips, Hine, \& Thorsteinsson, 2010). While this metaanalysis offered some support for the relation between interpretation biases and depression, the study focused on a small subset of relevant work in this area and did not aim to explore methodological or theoretical factors that may moderate this relationship. The field clearly lacks a comprehensive meta-analysis that synthesizes prior research findings on interpretation biases in depression. In an attempt to address this gap in the literature, this study aims (a) to estimate the magnitude of the overall effect size and (b) to explore whether effect sizes vary as a function of several key theoretical or methodological factors.

\section{Theoretical models of interpretation biases in depression}

To contextualize the variables of interest to this meta-analysis, this section briefly outlines several influential cognitive models of depression that have guided research on interpretation biases.

One of the most prevailing cognitive models is Beck's schema theory (Beck \& Haigh, 2014; Clark et al., 1999). This theory asserts that individuals who are vulnerable to depression hold latent negative schemas or memory representations that contain negative self-referent beliefs on themes of loss and failure. Negative schemas develop through interactions between cognitive processes and adverse environmental factors. When activated by stressful life events, negative schemas guide how individuals process and interpret information. Vulnerable and 
depressed individuals are theorized to selectively attend to negative cues in their environment and recall related negative experiences. These negative biases in attention and memory skew the integration of information and produce a stream of more negative and fewer positive interpretations. Such interpretation biases reinforce negative schemas and memories, instigating a vicious cycle of negative thinking and worsening of depressive mood.

Drawing on Bower's network theory (Bower, 1981), Ingram (1984) proposed an information-processing analysis in which interpretations play a central role in self-perpetuating circles of negative thought in depression. The theory assumes that interpretations of life events activate memory networks. These memory networks consist of a number of interconnected nodes containing specific sets of cognitions. It is assumed that the activation of specific nodes spreads to all other connected nodes within a certain memory network and all its related networks. This causes individuals to elaborate upon cognitions that are congruent with their initial interpretations, which in turn activate other related negative cognitions. The process of recycling negative interpretations through various memory networks is thought to heighten vulnerability to depression. Once negative interpretations are more frequently made, they can more easily trigger extensive elaboration on related negative topics and themes. Ingram's theory asserts that the biased elaboration on negative interpretation is a vulnerability factor that endures beyond the depressive episode.

Recent models of depression increasingly emphasize the role of mental imagery during emotional information-processing. While ambiguity can be resolved verbally, it can also be resolved through mental imagery. Holmes and colleagues (Holmes, Lang, \& Deeprose, 2009) formulated a model of depression that focuses on the interaction between mental imagery and interpretation bias. The model proposes that interpretation biases and mental imagery have particularly toxic effects on depressed mood when these factors interact. It is hypothesized that making a negative interpretation and subsequently mentally simulating it amplify depressed 
mood more than verbal interpretations of the same situation. The mental images constructed may in turn be interpreted negatively and increase depressive mood. In addition to negative mental images, the lack of positive mental imagery in depression may further contribute to the depressed mood. This is because it prevents formation of more positive images that can motivate goal-directed behavior. Mental imagery may thus be a critical factor that aggravates the impact of interpretation biases on depressive symptoms.

\section{Moderating variables derived from theoretical models}

Theoretical models converge on the hypothesis that depression is marked by interpretation biases. These models also propose a number of factors that influence the magnitude of the emotional bias in interpretation. Below, we focus on the clinical status of depression, the centrality of self-relevant stimuli, and the use of mental imagery. ${ }^{1}$

\section{Clinical status of depression}

Theories of depression predict that the magnitude of interpretation biases differs across depression groups (Beck \& Haigh, 2014; Clark et al., 1999; Ingram, 1984). In researching this hypothesis, studies have recruited samples of patients with diagnosed major depression, undiagnosed individuals with self-reported elevated levels of depressive symptoms, and patients remitted from major depression (Blanchette \& Richards, 2010; Foland-Ross \& Gotlib, 2012; Gotlib \& Joormann, 2010; Mathews \& Macleod, 2005; Wisco, 2009). In the face of more severe and impairing symptoms, theorists have argued that clinical depression is qualitatively different from subclinical symptom levels of depression (Ingram \& Siegle, 2009). Hence, patients with diagnosed major depression are expected to display more severe interpretation biases than undiagnosed individuals with elevated depressive symptoms. Moreover, theoretical models predict that biased elaboration of negative interpretations is a vulnerability factor that

\footnotetext{
${ }^{1}$ Cognitive models often make differential predictions regarding the levels of automaticity at which interpretation biases occur. This factor was not considered here because there is currently no consensus about the boundaries of 'automatic' (i.e., quick, effortless, unconscious) and 'controlled' (i.e., slow, effortful, conscious) interpretations. In addition, interpretation tasks are generally not able to unambiguously disentangle these types of interpretations.
} 
endures beyond the depressive episode (Ingram, 1984). Therefore, individuals remitted from depression are expected to display an interpretation bias. However, this bias in remitted depression may represent either a stable process that operates continuously or a latent process that is activated by stress or negative mood (Just, Abramson, \& Alloy, 2001). To date, it is unclear whether there are differences in the magnitude of interpretation bias between depression groups with a different clinical status.

\section{Centrality of self-relevance}

Depression-linked interpretation biases are assumed to be triggered by self-relevant information related to depressed people's negative schemas (Clark et al., 1999) or depressive memory networks (Ingram, 1984). While a direct test of this theoretical prediction requires ideographically relevant experimental stimuli, studies have utilized standardized self-referent information as a proxy of idiographic relevance. Self-referential stimuli make reference to the respondent's own character and his/her experience. Though prior work has suggested that interpretation biases mainly occur for self-referent stimuli (Wisco, 2009), research is inconclusive as to whether interpretation biases are elicited only in response to this type of stimuli. For example, some investigators have observed an interpretation bias for specific otherreferent stimuli (e.g., Wisco \& Nolen-Hoeksema, 2010), whereas other researchers reported no such evidence (Cowden Hindash \& Rottenberg, 2017). Given the centrality of self-relevance in cognitive theories, it is important to determine whether self-referential stimuli elicit an interpretation bias and if this bias can be elicited by stimuli that are not self-referent.

\section{The use of mental imagery}

In line with theories stipulating that mental imagery exacerbates interpretation bias in depression (Holmes et al., 2009), studies on interpretation biases have sometimes explicitly instructed participants to use mental imagery to resolve the ambiguous stimuli. The task instructions typically prompt participants to imagine the described situation and its outcome or 
to elaborate on images evoked by the presented stimulus materials including themselves as a central actor, that is a first-person perspective. To date, it remains unclear to what extent mental imagery instructions affect the relation between interpretation biases and depression. Prior research has generally produced mixed findings. For example, even when identical paradigms were employed with instructions to use mental imagery, some studies did observe evidence for depression-linked interpretation biases (Lawson, MacLeod, \& Hammond, 2002) whereas others did not (Käse et al., 2013). For both theoretical and methodological reasons, it is important to clarify whether instructing participants to create mental images to disambiguate the emotional information alters the strength of the relation between interpretation biases and depression.

\section{Methodological considerations and moderators}

In addition to moderators related to theory, investigators have repeatedly argued that the diversity in methods contributes to the variability in research findings (Blanchette \& Richards, 2010; Foland-Ross \& Gotlib, 2012). Indeed, studies on interpretation biases differ in how interpretation bias is measured and quantified in bias scores. ${ }^{2}$

\section{Measurement method}

Investigators have used direct and indirect measurement methods to study interpretation biases. Direct measurement involves methods that require respondents to report the emotional tone of their interpretation(s) in response to the stimuli presented. Examples of direct methods are interpretation tasks that ask respondents to report the interpretations they have constructed (Berna, Lang, Goodwin, \& Holmes, 2011; Wisco \& Nolen-Hoeksema, 2010) or to rank interpretations according to their plausibility (Butler \& Mathews, 1983). Importantly, direct methods are not restricted to questionnaires. Direct measurement of the emotional content of

\footnotetext{
${ }^{2}$ A variety of paradigms have been employed to study interpretation biases (for a recent overview, see Hirsch et al., 2016). These paradigms likely tap different aspects of interpretation bias and the type of paradigm may be a potential moderator of the relation between interpretation bias and depression. The type of paradigm was not considered as a moderator in this meta-analysis because the field lacks consensus regarding appropriate categories of paradigms and which aspects of interpretation bias they measure.
} 
interpretations is an important feature of many cognitive-experimental paradigms. For example, in the homograph task (Holmes, Lang, Moulds, \& Steele, 2008) or scrambled sentences task (Wenzlaff \& Bates, 1998), respondents describe the first mental image or thought that comes to mind. The advantage of direct methods is that they have higher face validity because they assess the content of emotional interpretations. This is information only respondents know. The major weakness is that direct methods are prone to response biases and demand characteristics (Blanchette \& Richards, 2010). This means that depressed individuals may preferentially endorse more negative interpretations, but that other factors than interpretation biases drive these effects (Blanchette \& Richards, 2010; Gotlib \& Joormann, 2010).

To minimize problems inherent to direct measurement methods, researchers have developed indirect measures. Indirect measures do not require respondents to describe or evaluate the content of their emotional interpretations. Instead, these measures rely on differential behavioral or psychophysiological responses to emotional interpretations. Examples of indirect measures include reaction times (Mogg, Bradbury, \& Bradley, 2006; Sears et al., 2011), startle responses (Käse et al., 2013; Lawson et al., 2002), and event-related potentials (Moser et al., 2012). Indirect methods are mostly employed by cognitiveexperimental paradigms. For instance, in the word-sentence association paradigm (Cowden Hindash \& Rottenberg, 2017), respondents judge the relatedness between pairs of words (e.g., 'embarrassing', 'funny') and ambiguous sentences (e.g., 'people laugh after something you said') that are presented for short durations (e.g., $500 \mathrm{~ms}$ ). The task records reaction times (RT) to endorse or reject the matched word-sentence pairs to infer interpretation bias. Evidence for an interpretation bias is inferred when faster RTs are found for endorsed negative wordsentence pairs compared to positive word-sentence pairs. The advantage of indirect measures is that they reduce the influence of potential response strategies on interpretation bias. The disadvantage is that they have lower face validity. 
To date, many studies in support of depression-linked interpretation biases have employed methods that directly measure interpretations, whereas the findings from studies with indirect measures have been mixed (Blanchette \& Richards, 2010; Foland-Ross \& Gotlib, 2012; Gotlib \& Joormann, 2010). Thus, examining the role of the measurement method as a moderator is of critical importance to determine whether methodological factors shape the conclusions regarding the relation between interpretation bias and depression.

\section{Interpretation bias scores}

Studies have computed both absolute and relative bias scores to represent depressionlinked biases in interpretation. Absolute bias scores are based on the recorded responses for each of the possible interpretations. For example, absolute bias scores may include the number of negative or positive interpretations reported (e.g., Halberstadt et al., 2008) or the reaction times on trials indexing positive, neutral, or negative interpretations (e.g., Bisson \& Sears, 2007). Other studies have calculated relative bias scores that directly compare negative and positive interpretations by calculating proportions or ratios (e.g., Moser, Huppert, Foa, \& Simons, 2012). The advantage of absolute over relative bias scores is that they allow disentangling valence-specific biases, namely decreased positive versus increased negative interpretations. Yet, relative bias scores may better quantify the depression-linked distortion in emotional information-processing (Shane \& Peterson, 2007). Indeed, toxic effects of a negative bias could be dependent on how this bias operates relative to the presence of positive interpretations. Comparing negative with positive interpretations may reveal larger effect sizes than absolute indexes. Examining the moderating role of the interpretation bias score is important to identify the specific interpretation biases in depression as hypothesized by theoretical models (Clark et al., 1999; Holmes et al., 2009; Ingram, 1984) as well as to gain insight in to how best to quantify the severity of distortions in the interpretation of ambiguous emotional information. 


\section{The present meta-analysis}

The purpose of this meta-analysis is to provide the first comprehensive and objective summary of a research on interpretation biases related to depression. The first objective is to assess the overall effect size of the relation between interpretation biases and depressive symptoms. The second objective is to examine theoretical and methodological factors that may moderate this relationship. As moderators, this meta-analysis examines the clinical status of depression, the role of self-referent stimuli, the use of mental imagery instructions, the measurement method, and the interpretation bias score. An exhaustive examination of interpretation biases in depression is necessary to be able to draw empirically-informed conclusions about the strength of the relation between depression and interpretation bias. This study may accordingly inform theory, research, and treatment.

\section{Method}

\section{Literature search strategies}

Complementary approaches were used to identify relevant articles. First, studies were collected through comprehensive searches of electronic databases PsycINFO, Embase, ISI Web of Science, Scopus, and PubMed through September 2016. To maximize coverage of the relevant studies, the following comprehensive search string was entered into the databases: (depress* OR dysphor*) AND (interpret* OR apprais* OR schema* OR process* OR cognitive OR affective) AND bias*. In addition, the databases were also searched using search strings combining the name of common interpretation bias paradigms (scrambled sentences test, homophone task, homograph task, ambiguous face identification task, recognition test, lexical decision task, interpretation bias questionnaires, word-sentence association task, ambiguous story and sentence completion tasks, grammar decision task, reading time task, semantic priming tasks) and (depress* OR dysphor*). Second, Google Scholar was searched using the search string (depress* OR dysphor*) AND ("interpretation bias" OR "interpretive bias") in 
order to identify studies that may not have be included in the PsycINFO, Embase, ISI Web of Science, Scopus, or PubMed databases. Third, unpublished studies were searched in electronic thesis and dissertation databases, namely ISI Web of Science, Open Access Theses and Dissertations, Open thesis, DART-Europe E-theses Portal, EThOS e-theses online service, and ProQuest dissertations. Here, we searched for available records until September 2016 using the same search string as for published work. Finally, reference lists of review articles (Blanchette \& Richards, 2010; Gotlib \& Joormann, 2010; Hirsch et al., 2016; Mathews \& Macleod, 2005; Wisco, 2009), a meta-analysis (Phillips et al., 2010), and eligible articles included in this metaanalysis were hand-searched to ensure that as many relevant studies were considered for inclusion. Each article was assessed for relevance based on the inclusion and exclusion criteria.

\section{Inclusion and exclusion criteria}

The following criteria were applied to select the studies for this meta-analysis. First, articles were full-text reports written in the English language. Second, articles were considered only if the reported research employed interpretation bias tasks that included ambiguous emotional stimuli and measured the emotional tone (i.e., negative or positive) of the interpretations. Regarding the stimuli, interpretation tasks were allowed to present verbal and/or visual stimuli. This is because interpretation (bias) is a semantic process that operates on mental representations that are not restricted to the verbal domain (e.g., use of mental images to resolve ambiguity). Of note, less ambiguous stimuli may also elicit varying interpretations among individuals (cf. Holmes, Mathews, Dalgleish, \& Mackintosh, 2006). However, this metaanalysis is restricted to interpretation biases that have been studied in the context of ambiguity resolution to accord with the majority of research on interpretation biases in psychopathology (see Hirsch et al., 2016) and influential cognitive models of depression (e.g., Clark et al., 1999; Ingram et al., 1999). Studies presenting no ambiguous stimuli or studies that have probed emotional interpretations of neutral information are beyond the scope of this meta-analysis. 
Third, articles were included if the reported research included at least one sample of individuals with major depression, dysthymic disorder, remitted depression, or self-reported elevated levels of depressive symptoms. The clinical status of major depression and dysthymic disorder had to be assessed through clinical interview (e.g., Structured Clinical Interview for DSM-5; First, Williams, Karg, \& Spitzer, 2015). The term ‘clinical depression' will be used to refer to individuals meeting the diagnostic criteria for major depression and dysthymic disorder according to the Diagnostic and Statistical Manual of Mental Disorders (American Psychiatric Association, 2013). The status of remitted depression had to be determined through clinical interview and/or validated questionnaires (e.g., Diagnostic Inventory for Depression; Zimmerman, Sheeran, \& Young, 2004) to ensure that criteria for clinical depression were met in the past and not currently. Elevated levels of depressive symptoms in undiagnosed individuals had to be measured by validated questionnaires with established cutoff scores (e.g., a score $\geq 14$ on the Beck Depression Inventory - II; Beck, Steer, \& Brown, 1996). Studies assessing depression with single-item scales were not eligible because such measures do not provide a representative assessment of the heterogeneous symptoms of depression. Studies were excluded if the sample or participant recruitment featured one of the following characteristics: (a) the sample included individuals with bipolar disorder, (b) the sample involved patients with a principal diagnosis other than depression, (c) participant selection was based on other criteria than depressive symptoms, and (d) the sample involved healthy individuals in which depressive mood was experimentally induced.

Fourth, articles were considered if the reported research adopted a categorical study design comparing interpretation biases in non-depressed or never-depressed samples versus samples of undiagnosed individuals reporting elevated depressive symptoms, clinical or remitted depression. In addition, articles were considered if the reported research adopted a 
dimensional study design to examine interpretation bias along the continuum of depressive symptom severity.

Fifth, we restricted the focus of this meta-analysis to studies including adult samples with ages ranging between 18 and 65 years. Studies that exclusively focused on children, adolescents, and older adults were excluded. Age criteria were applied because developmental factors may influence the process of interpretation and its emotional biases (e.g., age-related differences in executive functions and positivity biases).

Finally, articles were only considered if depression was examined in relation to naturally occurring interpretation biases. When investigations involved procedures aimed at inducing or reducing interpretation biases through cognitive training (Hirsch et al., 2016), only data from the baseline measurements were considered.

\section{Selection of studies}

The PRISMA flow diagram depicted in Figure 1 illustrates the literature search and winnowing process. A total of 17,136 records were identified through database searches and 3,378 records were identified through other sources. After removing duplicates, the titles and abstracts of 7,934 papers were inspected according to the inclusion and exclusion criteria. This reduced the number of relevant articles to 162. The full-text articles were read and assessed for eligibility. This further reduced the number of relevant articles to 82 . In cases where an article met the listed criteria but reported insufficient data, the authors were contacted to provide the data required for inclusion. Studies were excluded if data necessary for inclusion were not retrieved. This resulted in the exclusion of 5 articles. A total of 77 articles reporting 87 independent studies (80 published, 7 unpublished) with 9,443 participants and 96 comparisons were included.

The first and second author conducted the selection process independently to ensure its reliability. Both raters judged the relevance of all records based on the outlined criteria. The 
interrater agreement was very good (kappa=.97). Cases of disagreement were solved through discussion until full agreement was obtained.

\section{Data coding system}

Table 1 presents the characteristics of the published and unpublished studies included in this meta-analysis. A standardized coding system was applied to every study. For each research report, we coded the following study characteristics: author information, year of publication, journal, and whether the article was published or not. Regarding the sample characteristics, we coded total sample size, gender composition, and mean age of the sample. For studies employing categorical and dimensional study designs, we separately coded the characteristics related to depressive symptom severity or depression groups. For categorical studies, we coded clinical status of the depression groups (i.e., undiagnosed elevated depressive symptoms, clinical depression, and remitted depression), clinical assessment procedure (i.e., clinical interview), group comparisons, and group sizes. For dimensional studies, we coded symptom assessment procedure and mean symptom severity. Moreover, the following moderators were coded: clinical status of depression (i.e., undiagnosed elevated depressive symptoms, clinical depression, remitted depression; only for studies that have used a categorical study design), self-reference of stimulus materials (i.e., self-referent, not-self-referent), the use of mental imagery instructions (i.e., yes, no), measurement method (i.e., direct versus indirect), computed interpretation bias score (i.e., absolute positive, absolute negative, relative indexes), and study design (i.e., dimensional, categorical).

The first and second author extracted the study characteristics and checked for accuracy. With kappa's ranging from .84 to .100 , good to very good interrater reliability was found. Disagreements were resolved by discussion until consensus was reached. 


\section{Methodological quality assessment}

The quality of included studies was assessed using a rating scale based on Downs and Black's Checklist for Measuring Quality (Downs \& Black, 1998). This rating scale for nonrandomized designs was recently adapted for use in meta-analytic research on interpretation biases toward illness-related information (Hughes, Hirsch, Chalder, \& Moss-Morris, 2016). The adapted Checklist for Measuring Quality contained the highest number of relevant items to this review (see Appendix S1). The ratings scale consisted of 18 items assessing the quality in terms of reporting, external validity, internal validity, confounders, and power of the study. Each criterion is rated on a two-point scale (0/no, 1/yes), with higher scores indicating superior quality. Two independent researchers conducted the ratings. Acceptable inter-rater agreement was found (kappa=.74). Disagreements were solved by discussion, and the final coding reflected consensus.

\section{Meta-analytic procedures}

Statistical analyses were based on Hedges's $g$, which provides better estimates of effect sizes for small sample studies (Hedges \& Olkin, 1985). Similar to the Cohen's $d$ coefficient, a Hedges's $g$ value between $0.2-0.5$ indicates a small effect size (ES), a value between $0.5-0.8$ points to a medium ES, and values of 0.8 or larger indicate a large ES (Cohen, 1988). All ESs were coded such that a positive value of Hedges's g points to a more negative or less positive interpretation bias. If interpretation bias was measured by more than one instrument, the average ES for the measures was first computed within a study (accounting for the correlation between the measures).

We calculated the pooled ES across studies using Comprehensive Meta-Analysis (version 3.3.070, Biostat, Englewood, NJ). The mean ESs were preferentially extracted from means, standard deviations and sample sizes, as well as correlations coefficients. If these data were not available, we calculated the ES by using the available statistics: reported Cohen's $d$ 
values, between-group $t$ values and sample sizes, between group $p$ values and degrees of freedom, Fisher's Z along with sample sizes.

ES estimates were extracted from both categorical and dimensional study designs. For studies employing a categorical design, we computed the ES indicating the difference in interpretation bias between the depressed (i.e., undiagnosed elevated depressive symptoms, clinical, remitted) and the non-depressed groups. The ESs were computed by subtracting the average score of the depressed group from the average score of the non-depressed group, and dividing the result by the pooled standard deviation of the two groups. For dimensional designs, all ES computations were performed based on Fisher's $\mathrm{z}$ transformation of the correlation coefficients. We created a unitary/pooled set of effect sizes combining data from categorical and dimensional study designs in light of converging results from separate analyses. This approach was chosen in light of converging results from separate analyses of the data sets from categorical and dimensional studies. Note that we controlled for over-inflation of mean ESs caused by expressing the same results in a dimensional and categorical manner by randomly excluding one of the indexes. When a study reported more than one level of a moderator (e.g., both absolute indexes of bias), dependencies were accounted for by randomly selecting one within-study level per moderator (Hunter \& Schmidt, 2004). This technique enabled independent analysis at the moderator level.

As we expected a considerable degree of heterogeneity among studies, we calculated mean effect sizes using a random-effects model in all analyses (Riley, Higgins, \& Deeks, 2011). Homogeneity was assessed with the $I^{2}$-statistic, which indicated the percentage of observed heterogeneity. A value of $0 \%$ indicates no heterogeneity, values $\leq 25 \%$ indicate low heterogeneity, values $\leq 50 \%$ indicate moderate heterogeneity, and values $\geq 75 \%$ indicate high heterogeneity (Borenstein, Hedges, Higgins, \& Rothstein, 2009). We calculated 95\% confidence intervals (CI) around $I^{2}$ using the heterogi module for Stata (Orsini, Bottai, Higgins, 
\& Buchan, 2006). In order to estimate the pooled ES with and without outliers, we defined outliers as being studies in which the $95 \%$ CI was outside the $95 \%$ CI of the pooled ES for all studies (two-sided).

We conducted moderator analyses testing the following variables: clinical status of depression (for categorical studies only), self-reference of stimuli, use of mental imagery instructions, measurement method, computed interpretation bias score, year of publication, study design, and methodological quality. Mixed-effects models were used to test categorical moderators. Meta-regression analyses using a restricted maximum likelihood model with the Knapp-Hartung method tested the continuous moderators (Borenstein et al., 2009).

We examined publication bias in three ways. First, we visually inspected funnel plots, which display the standard error for each study against the study's ES. In the presence of a publication bias, there would be a higher concentration of studies at the lower side of the plot. Second, we used the Duval \& Tweedie trim-and-fill procedure (Duval \& Tweedie, 2000). This procedure provides corrected ESs and confidence intervals that account for these missing studies based on the asymmetry in the funnel plot (Borenstein et al., 2009; Duval \& Tweedie, 2000). Finally, we used Egger's test of the intercept to test significance of the asymmetry of the funnel plot (Sterne, Becker, \& Egger, 2006). When there is no evidence of funnel plot asymmetry, the intercept is not significantly different from zero (Sterne et al., 2006).

\section{Results}

\section{Characteristics of the studies}

Sample sizes ranged from 7 to 1,173 totaling 9,443 participants. The mean age ranged from 18 to 44.81 years and the proportion of female participants ranged from $55.1 \%$ to $100 \%$. The number of studies with a dimensional design $(\mathrm{k}=41)$ was comparable to the number of studies with a categorical design $(\mathrm{k}=46)$. With regard to task properties, most studies relied on 
direct measurement methods $(\mathrm{k}=67)$, computed absolute bias scores $(\mathrm{k}=51)$, presented selfreferent stimuli $(\mathrm{k}=62)$, and did not provide mental imagery instructions $(\mathrm{k}=61)$.

\section{Methodological quality}

The average overall quality rating was $75.68 \%(S D=9.43)$ with ratings ranging from $47.37 \%$ to $94.74 \%$. Table 2 presents the average scores on the items of the checklist. The table reveals lower scores for the item assessing whether the studies tested participants' engagement with the task(s) and items related to the quality of reporting (confounders, exact probability values, withdrawals/drop-outs, and power analysis).

\section{Overall effect size}

Table 3 presents detailed statistics of the analyses examining the overall ES. The mean pooled ES of the 87 studies examining interpretation bias in relation to depression rendered a medium Hedges' g score $(\mathrm{g}=0.72, \mathrm{p}<.001)$. Extracting the 13 outlying studies that did not overlap with the $95 \%$ CI of the pooled ES, did not substantially alter the overall Hedges' $g$ score $(\mathrm{g}=0.74, \mathrm{p}<.001)$. Heterogeneity was high $\left(\mathrm{I}^{2}=75 \%\right)$ for the overall pooled ES and medium $\left(\mathrm{I}^{2}=50 \%\right)$ after removing outlying studies. These results remained unaltered when conducting a 'remove one' analysis in Comprehensive Meta-Analysis (Borenstein et al., 2011) to gauge the impact of each study. Figure 2 depicts the ES for each study and the 95\% CI around the ES.

\section{Moderator analyses}

Table 3 presents the results of the moderator analyses for both theoretical and methodological variables. For the theoretical moderators, mixed-effects models revealed that the self-referent nature of the stimuli significantly moderated the relation between interpretation bias and depression. Studies presenting self-referent stimuli yielded significantly larger ESs than studies using tasks that do not present self-referent stimuli. Yet, the small ES for studies not presenting self-referent stimulus materials was still significant. Neither the clinical status of depression nor the use of mental imagery instructions was a significant moderator. As shown 
in Table 3, ESs were not significantly different among studies in clinical depression, remitted depression, or undiagnosed elevated depressive symptoms. The ESs for each of the depressed groups were significant and in the medium range. Moreover, regarding use of mental imagery instructions, equivalent medium significant ESs were observed for studies that did or did not provide mental imagery instructions to resolve the ambiguous emotional information.

For methodological moderators, the mixed-effect models demonstrated that both the measurement method and the computed interpretation bias score had a significant effect on the relation between interpretation bias and depression. Regarding measurement method, the ES was only significant for studies using direct measurement methods. Studies employing indirect methods produced a non-significant ES. Moreover, the computed bias index was a significant moderator. As shown in Table 3, larger ESs were observed for studies computing relative bias scores compared to studies computing absolute positive or negative bias scores. The ESs for studies using relative bias scores as well as studies using absolute bias scores were significantly different from zero. Finally, the study design was a significant moderator. Larger ESs were found for dimensional study designs compared to categorical study design (see Table 3 ). ${ }^{3}$

\section{Risk of bias}

There were some indications for a small positive effect of publication bias. The Duval \& Tweedie trim and fill procedure inputted 11 studies with ESs below the mean. This is also visible from the funnel plot in Figure 3 (black dots indicate inputted missing studies). After adjustment for publication bias according to Duval and Tweedie's trim and fill procedure, the overall ES was reduced from 0.72 (see Table 3$)$ to 0.63 (95\%-CI: [0.53; 0.74]). This adjusted overall ES remained significant and within the medium range. Egger's test for the asymmetry in the funnel plot was not significant (intercept=-0.59, 95\%-CI: [-1.61;0.42], $\mathrm{p}=0.25$ ).

\footnotetext{
${ }^{3}$ Sensitivity analyses yielded converging results with respect to significant moderators from separate analyses of the data sets from categorical and dimensional studies, and are therefore not reported here.
} 
Moreover, we further assessed the risk of bias by performing meta-regression analyses testing the effect of methodological quality of the included studies and publication year on the relation between interpretation bias and depression. Neither methodological quality (slope $\mathrm{b}=0.01,95 \%-\mathrm{CI}:[-0.01 ; 0.02], \mathrm{p}=0.42)$, nor publication year (slope $\mathrm{b}=0.03,95 \%-\mathrm{CI}:[-0.01$; 0.01], $\mathrm{p}=0.55$ ) moderated the ES, even when the effect of the other variable was held constant.

\section{Discussion}

Intense research during the past four decades has generated a wealth of data on the relation between interpretation biases and depression. Yet, empirical findings have been mixed and investigators have drawn diverging conclusions regarding the strength of the available evidence. This study aimed to provide the first comprehensive meta-analysis to assess the current state of research in this field of interest. In line with theoretical predictions (Clark et al., 1999; Holmes et al., 2009; Ingram, 1984), prior reviews (Mathews \& Macleod, 2005; Wisco, 2009), and a meta-analysis (Phillips et al., 2010), the results revealed a medium ES supporting the hypothesized interpretation biases linked to depression. However, there was medium to high heterogeneity of the pooled ES. This was expected given the nature of interpretation bias as a complex higher-order cognitive process and the methodological diversity that characterizes interpretation bias tasks. Several a priori identified moderators related to theory and methodology were examined to determine the sources of this heterogeneity.

\section{Moderators of interpretation biases in depression}

\section{Clinical status of depression}

In contrast to the prediction that the magnitude of interpretation biases differs across depression groups (Beck \& Haigh, 2014; Clark et al., 1999; Ingram, 1984), this meta-analysis found that the clinical status of depression did not moderate the relation between depression and interpretation bias. The ESs for interpretation bias in samples of undiagnosed individuals with elevated depressive symptoms, patients with clinical depression, and patients remitted 
from depression were equivalent for each of the depressed groups. However, the lack of evidence for differences in ESs between depression groups suggests that a strict clinical cutoff may be of little significance. ${ }^{4}$

The fact that a significant ES was observed for remitted depression supports the notion that interpretation biases are not mere correlates of a depressive mood state. In line with predictions by cognitive models (Clark et al., 1999; Ingram, 1984), interpretation biases may remain present after the depressive episode. Of note, remission designs are not conclusive with respect to whether interpretation bias represents a scar or a vulnerability factor (Just et al., 2001). Even if interpretation bias would be a vulnerability factor that occurs in remitted depression, then it still is unclear whether the bias represents a factor that operates constantly vs. a latent factor that is triggered by stress or negative mood states (Ingram \& Siegle, 2009). Current studies are limited in their ability to address this question. Though a majority of studies in remitted depressed individuals did not utilize mood induction procedures (for one exception, see Van der Does, 2005), it cannot be concluded that a negative mood is not necessary to elicit interpretation biases because residual depressive symptoms may have triggered the interpretation biases. Future work needs to reveal whether interpretation biases reflect a scar or vulnerability factor using priming designs that simulate the activation of the interpretation bias in response to stress as well as longitudinal behavioral high-risk studies to examine if interpretation biases occur before a depressive episode and prospectively predict its onset.

\section{Centrality of self-relevance}

The moderating role of self-reference indicates that the nature of stimuli that prompt interpretation is important in eliciting a depression-linked bias. Interpretation biases were particularly strong for self-referent stimuli. This is consistent with the prediction that stimuli

\footnotetext{
${ }^{4}$ Inspection of depressive symptoms levels in undiagnosed individuals revealed that these samples had, on average across studies, only moderate severity. The lack of significant differences in ESs from studies in clinical vs. undiagnosed samples is thus less likely accounted by similar depression severity.
} 
relevant to people's negative schemas (Clark et al., 1999) or memory networks (Ingram, 1984) produce the emotional bias in interpretation. This finding provides quantitative evidence for similar conclusions reached in a prior narrative review (Wisco, 2009).

Interestingly, the findings revealed that depressed individuals also interpret ambiguous information that is not self-referent in a more negative and/or less positive manner. This observation is indicative for a general bias to endorse negative interpretations (Mathews \& Macleod, 2005). However, it cannot be excluded that stimuli that are not directly self-referent become imbued with personal meaning through self-reflection by depressed individuals (Mor $\&$ Winquist, 2002). Nonetheless, the finding that both self-referent and not self-referent stimuli may elicit depression-linked interpretation biases points to the importance of careful stimulus selection. Important sources of noise may be due to stimuli that do not adequately reflect the concerns relevant to depression, or not self-referent stimuli that allow respondents to ascribe largely varying meanings. These sources of noise may result in an underestimation of the ES or produce null-findings. This issue may be particularly important for cognitive-experimental paradigms of interpretation bias which often do not systematically present self-referent or ideographically self-relevant stimulus materials.

\section{Use of mental imagery}

Mental imagery instructions did not modify the ESs of relation between interpretation biases and depression. Equivalent (significant) ESs were observed for studies that provided mental imagery instructions and studies that did not do so. This is surprising given that the studies included in this meta-analyses instructed participants to create mental images involving themselves as a central actor, which is expected to enhance self-relevance and thereby interpretation bias. This observation does not confirm theories advocating that mentally simulating negative outcomes amplifies depressed mood (Holmes et al., 2009). However, this finding cannot rule out that mental imagery is not an important factor in the process of 
interpretation. This is because many studies on interpretation bias do not use explicit instructions to abstain from mental imagery. Consequently, these studies cannot exclude the possibility that participants spontaneously used mental imagery when resolving the ambiguity of the presented stimuli. To understand the role of mental imagery in interpretation bias, it is important that studies quantify the extent to which mental imagery is involved in the interpretation bias task as well as the imagery perspective (i.e., first-person vs. third-person).

\section{Measurement method}

The measurement method moderated the relation between depression and interpretation biases. Larger ESs were observed for studies using direct methods, which require respondents to report the emotional tone of their interpretation(s). The non-significant ES for indirect measurement methods indicates that these methods have not provided reliable evidence for interpretation biases in depression and interpretation biases. These results suggest that methodrelated factors shape the conclusions and accord with skeptical opinions about the strength of the evidence for interpretation biases in depression (Blanchette \& Richards, 2010; Foland-Ross \& Gotlib, 2012; Gotlib \& Joormann, 2010).

Based on these results, it could be argued that conclusions stating that depression is marked by interpretation biases are premature (Blanchette \& Richards, 2010; Foland-Ross \& Gotlib, 2012; Gotlib \& Joormann, 2010). This is because direct methods are susceptible to response biases and demand characteristics, and studies that tried to overcome these limitations by using indirect methods failed to provide evidence. Hence, it is possible that depressed individuals are inclined to report more negative and less positive interpretations due to factors related to anhedonia (e.g., loss of pleasure, loss of interest), which causes them to engage less in considering all attributes of a situation and to report default negative responses. This process may occur regardless of the encountered situation and interpretation processes serving to explain the situation. 
Alternatively, it could be argued that the applied indirect measures do not adequately capture the essence of interpretation biases in depression. While self-reports directly measure the content of emotional interpretations, indirect measures such as reaction times, ERP components, or startle reflexes provide an index that reflects the association between multiple stimuli presented (e.g., an ambiguous cue and a disambiguating target). Based on these associations, it is inferred what type of interpretations participants have generated. This remains an approximation of the content of the inferred interpretation. Moreover, there are also specific difficulties associated with certain indirect measures. For example, indexes based on reaction times are subject to variability in motor responses associated with elevated depression levels and these could mask subtle reaction time differences. Unfortunately, investigators do not routinely apply methods to (partly) address this problem (Faust, Balota, Spieler, \& Ferraro, 1999). It is important to note, however, that this meta-analysis found an interpretation bias in remitted depressed individuals, which suggests that interpretation biases are also present in the absence of strongly elevated depression levels. This argues against the response bias explanation for the findings, though it cannot be excluded that residual symptoms exert an influence on interpretation bias and set the stage for response biases.

In sum, depression is associated with interpretation biases, but it cannot be ruled out that other factors than interpretation biases (partly) account of the present evidence base. This warrants a more nuanced view on strength of the evidence for such biases in depression.

\section{Interpretation bias scores}

Consistent with the prediction that depression features a tendency to impose more negative and fewer positive interpretations (Beck \& Haigh, 2014; Clark et al., 1999; Holmes et al., 2009; Ingram, 1984), the analyses revealed that higher depression levels were linked to decreased positive and increased negative interpretations. Both biases had equivalent ESs. Hence, it is not surprising that relative bias scores comparing negative versus positive 
interpretations produced a larger ES than the absolute bias indexes. Relative bias scores may represent more powerful indices to quantify the severity of the distortions in emotional information-processing (Shane \& Peterson, 2007), including emotional interpretations of ambiguous information. However, both relative and absolute indexes have their merit. Whereas relative biases powerfully capture the emotional distortions, absolute indexes disentangle the lack of a positive bias or the presence of a negative bias.

\section{Methodological quality and risk of bias}

The average methodological quality of the studies was high. Yet, there is room for improvement given that various research reports failed to clarify how they handled missing data and determined sample size (e.g., power calculations). If not reported, this missing information may represent a threat to the transparency and replicability of research findings in this area. Importantly, neither methodological quality nor publication year moderated the overall ES. This suggests that the risk of bias caused by the variability in methodological quality or the time when a study was published is minimal.

Though unpublished reports and null-findings were included in this meta-analysis to reduce the risk of publication bias, there is an indication that studies with non-significant results are less likely to be published. However, the adjusted ES remained significant and in the medium range. This suggests that publication bias was not a large concern in this meta-analysis.

\section{Clinical implications}

The present findings have implications for cognitive training methods aimed at ameliorating interpretation biases in depression. These methods train individuals in resolving ambiguous emotional information in a benign manner through repeated practice (Hirsch et al., 2016). While some evidence indicates that these procedures reduce interpretation biases (Menne-Lothmann et al., 2014), the effect on mental health problems may be limited (Cristea 
et al., 2015). This suggests that there is ample room for improvement. The results of this metaanalysis may provide some clues to advance this field.

In light of the finding that interpretation biases are particularly expressed for selfreferent information, training procedures may need to encourage self-referential processing during training by referring to participants' own character and daily life. Engaging participants in self-referent processing may increase the beneficial impact of newly formed positive interpretations. This is because self-reference may increase the saliency of the incongruence with a negative interpretation bias. Though ambiguous stimuli are self-referent in most training procedures (Möbius, Tendolkar, Lohner, Baltussen, \& Becker, 2015; Williams, Blackwell, Mackenzie, Holmes, \& Andrews, 2013), these procedures vary in the extent to which the disambiguating positive outcomes make explicit reference to the respondent. Processing the positive outcomes in a self-referent manner could be particularly important to boost the effectiveness of the training.

Moreover, the finding that the measurement method altered the strength of the relation between depression and interpretation bias has important consequences for these training procedures. If evidence for interpretation biases in depression continues to be tied to direct measurement methods and thus remains subject to alternative explanations, then this could become a threat for the internal validity of procedures that aim to modify interpretation bias. That is, if there is no unambiguous evidence for interpretation bias, then it renders unclear which processes are in fact targeted and altered by these training procedures. Indeed, most training studies assess the effectiveness of the training procedure using direct measurement methods (for an excpetion, see Möbius et al., 2015), and thus the interpretation of the results in terms of the active working mechanism is subject to the same limitations that apply to the interpretation bias tasks. Therefore, studies that aim to modify interpretation biases may need to integrate both direct and indirect measurement methods in a task independent from the 
training. This is to assess their correspondence and gain insight into the possible mechanisms involved in interpretation bias training.

\section{Methodological recommendations}

Several methodological considerations deserve future attention. First, research needs to study the correspondence between direct and indirect measures of interpretation bias within single paradigms (Cowden Hindash \& Amir, 2012; Käse et al., 2013; Moser et al., 2012). This is important to understand whether these measures reflect the same underlying process. While some correspondence between these measures is expected, direct and indirect indexes may only have weak to moderate correlations when they are used to tap different aspects of interpretation. For example, indirect measures may be better suited to tap the unintentional (i.e., interpretations are formed irrespective of current goals), unconscious (i.e., the interpretation process occurs outside awareness), efficient (i.e., the interpretation process recruits minimal cognitive resources), and/or uncontrollable (i.e., limited ability to stop the interpretation process) interpretations (Teachman, Joormann, Steinman, \& Gotlib, 2012). Direct measures are simply be less suitable for such purposes. In addition, it deserves future study to identify if some indirect measures are more suitable to tap specific biases in the process of interpretation (e.g., unintentional, uncontrollable interpretations).

Second, future research may need to characterize the nature of the interpretation biases involved in many of the commonly-used interpretation tasks. This seems important in light of the large diversity in questionnaires and experimental paradigms used to assess the bias (Hirsch et al., 2016). It is likely that different tasks tap into different aspects of interpretation bias. Interpretation involves the subprocesses of generation and selection of meanings that are plausible in a particular situation (Wisco, 2009). Both the generation and selection of interpretations may occur in an intentional versus unintentional, conscious versus unconscious, inefficient versus efficient, and/or controllable versus uncontrollable manner. Yet, there is 
currently little consensus which tasks best measure these different aspects of the interpretation process and its bias. Relatedly, little is known about the validity and reliability of interpretation bias paradigms. To address this issue, a detailed conceptual analysis of interpretation bias tasks is required as well as studies that examine their psychometric properties. These endeavors will allow future meta-analyses to identify sources of heterogeneity.

A last recommendation relates to the comparison conditions used to infer interpretation bias in depressed groups. That is, the magnitude of the interpretation bias is often based on a comparison of depressed individuals with non-depressed controls, but the composition of the control groups varies across studies. Non-depressed individuals are usually sampled from the community, student populations, or both based on varying operational definitions. "Nondepressed" may refer to low self-reported scores on a questionnaire, not meeting diagnostic criteria for major depression, or not meeting clinical criteria with no history of depression. The variability in the type of non-depressed participants may explain some of the variability in the strength of the ESs. However, most research does not report (or assess) details regarding the non-depressed sample. Future research needs to provide detailed descriptions of the control group(s) included in the study.

\section{Limitations}

Several limitations should be acknowledged. First, we cannot rule out that the sample of included studies is not representative for all studies that have been conducted to investigate the relation between depression and interpretation bias. We attempted to minimize the possibility of missing relevant articles by performing comprehensive systematic searches in various online databases and by soliciting unpublished research. Importantly, the publication bias analyses indicated this was not a major concern.

Second, there was considerable heterogeneity of the pooled ESs and a priori identified moderators were not able to fully explain this heterogeneity. This suggests other factors not 
examined in this meta-analysis had an influence. The fact that there were unaccounted levels of heterogeneity is an important observation, in particular because this meta-analysis tested key theoretical and methodological variables which were identified a priori. Therefore, this limitation not only applies to this meta-analysis, but represents a limitation that characterizes the current literature in this field of interest. As outlined in previous sections, this meta-analysis identified several methodological and theoretical challenges to understand the nature of interpretation biases. Addressing these challenges may enable future meta-analyses to explain larger proportions of study heterogeneity. Despite this limitation, it should be noted that sensitivity analyses on the separate sets of categorical and dimensional studies yielded similar results. This adds to the reliability of the findings even in the face of the heterogeneity.

Finally, this meta-analysis included data from cross-sectional studies examining associations between depression and interpretation bias. This precludes inferences regarding causality. The presented evidence for a link between interpretation bias and depression does not imply that interpretation bias causes depression as is proposed by some theoretical models. This requires experimental studies that manipulate interpretation biases and examine its influence on depressive symptoms of depression (Cristea et al., 2015; Menne-Lothmann et al., 2014). Yet, these methodologies also face a number of challenges and the present meta-analyses may inform the next steps to advance this field.

\section{General conclusion}

The following conclusions are supported by this meta-analysis. First, there is evidence that depression is associated with interpretation biases, but caution is necessary because the evidence draws on studies using direct methods. Second, there is no evidence that the magnitude of interpretation differs across individuals with undiagnosed elevated depressive symptoms, clinical, or remitted depression. Third, interpretation biases are stronger for self-referent stimuli, but also occur for stimuli that are not self-referent. Fourth, mental imagery instructions 
during the interpretation task do not influence the relation between depression and interpretation biases. Finally, interpretation biases are marked by fewer positive and more negative meanings, which can be combined into a relative bias to comprehensively capture depression-linked biases in interpretation. These findings have important theoretical, methodological, and clinical implications that warrant further research. 


\section{References}

American Psychiatric Association. (2013). Diagnostic and statistical manual of mental disorders (5th ed.). Washington, D.C.: American Psychiatric Association.

Beard, C., Rifkin, L. S., \& Björgvinsson, T. (2017). Characteristics of interpretation bias and relationship with suicidality in a psychiatric hospital sample. Journal of Affective Disorders, 207, 321-326. https://doi.org/10.1016/j.jad.2016.09.021

Beck, A. T., \& Haigh, E. A. P. (2014). Advances in cognitive theory and therapy: The generic cognitive model. Annual Review of Clinical Psychology, 10(1), 1-24.

https://doi.org/10.1146/annurev-clinpsy-032813-153734

Beck, A. T., Steer, R. A., \& Brown, G. K. (1996). Manual for the Beck Depression InventoryII. San Antonio, TX: Psychological Corporation.

Beevers, C. G., Wells, T. T., Ellis, A. J., \& Fischer, K. (2009). Identification of emotionally ambiguous interpersonal stimuli among dysphoric and nondysphoric individuals. Cognitive Therapy and Research, 33(3), 283-290. https://doi.org/10.1007/s10608-0089198-6

Beharomitrani, V., Carver, C. S., Ganellen, R. J., Behar-Mitrani, V., \& Beharomitrani, V. (1985). Depression and cognitive style: comparisons between measures. Journal of Personality and Social Psychology, 49(3), 722-728. https://doi.org/10.1037/00223514.49.3.722

Belli, S. R. (2013). “Why bother? It's gonna hurt me”: The role of interpersonal cognitive biases in the development of anxiety and depression. ProQuest Dissertations \& Theses.

Berking, M., Ebert, D., Cuijpers, P., \& Hofmann, S. G. (2013). Emotion regulation skills training enhances the efficacy of inpatient cognitive behavioral therapy for major depressive disorder: A randomized controlled trial. Psychotherapy and Psychosomatics, 82(4), 234-245. https://doi.org/10.1159/000348448 
Berna, C., Lang, T. J., Goodwin, G. M., \& Holmes, E. A. (2011). Developing a measure of interpretation bias for depressed mood: An ambiguous scenarios test. Personality and Individual Differences, 51(3), 349-354. https://doi.org/10.1016/j.paid.2011.04.005

Bisson, M. A. S., \& Sears, C. R. (2007). The effect of depressed mood on the interpretation of ambiguity, with and without negative mood induction. Cognition \& Emotion, 21(3), 614-645. https://doi.org/10.1080/02699930600750715

Blackwell, S. E., Browning, M., Mathews, A., Pictet, A., Welch, J., Davies, J., ... Holmes, E. A. (2015). Positive imagery-based cognitive bias modification as a web-based treatment tool for depressed adults. Clinical Psychological Science, 3(1), 91-111. https://doi.org/10.1177/2167702614560746

Blackwell, S. E., \& Holmes, E. A. (2010). Modifying Interpretation and Imagination in Clinical Depression: A Single Case Series Using Cognitive Bias Modification. Applied Cognitive Psychology, 24(3), 338-350. https://doi.org/10.1002/acp.1680

Blanchette, I., \& Richards, A. (2010). The influence of affect on higher level cognition: A review of research on interpretation, judgement, decision making and reasoning. Cognition \& Emotion, 24(4), 561-595. https://doi.org/10.1080/02699930903132496 Blaney, P. H., Behar, V., \& Head, R. (1980). Two measures of depressive cognitions: Their association with depression and with each other. Journal of Abnormal Psychology, 89(5), 678-682. https://doi.org/10.1037/0021-843X.89.5.678

Borenstein, M., Hedges, L. V., Higgins, J. P. T., \& Rothstein, H. (2009). Introduction to meta-analysis. Chichester, UK: Wiley.

Borenstein, M., Hedges, L. V., Higgins, J., \& Rothstein, H. (2005). Comprehensive metaanalysis Version 2 [Computer software]. Englewood, NJ: Biostat.

Bos, E. H. (2005). Interpersonal mechanisms in recurrence of depression. Dissertation Abstracs International. 
Bower, G. H. (1981). Mood and memory. American Psychologist, 36(2), 129-148. https://doi.org/10.1037/0003-066X.36.2.129

Bowler, J. O., Mackintosh, B., Dunn, B. D., Mathews, A., Dalgleish, T., \& Hoppitt, L. (2012). A comparison of cognitive bias modification for interpretation and computerized cognitive behavior therapy: effects on anxiety, depression, attentional control, and interpretive bias. Journal of Consulting and Clinical Psychology, 80(6), 1021-1033. https://doi.org/10.1037/a0029932

Butler, G., \& Mathews, A. (1983). Cognitive processes in anxiety. Advances in Behaviour Research and Therapy, 5(1), 51-62. https://doi.org/10.1016/0146-6402(83)90015-2

Clark, D. A., Beck, A. T., \& Alford, B. A. (1999). Scientific foundations of cognitive theory and therapy of depression. New York: John Wiley \& Sons.

Cohen, J. (1988). Statistical power analysis for the behavioural sciences. Hillsdale, NJ: Lawrence Earlbaum Associates. https://doi.org/10.1234/12345678

Cooper, J. L., Wade, T. D., \& Cooper, J. L. (2015). The Relationship Between Memory and Interpretation Biases, Difficulties with Emotion Regulation, and Disordered Eating in Young Women. Cognitive Therapy and Research, 39(6), 853-862. https://doi.org/10.1007/s10608-015-9709-1

Cowden Hindash, A. H., \& Amir, N. (2012). Negative interpretation bias in individuals with depressive symptoms. Cognitive Therapy and Research, 36(5), 502-511. https://doi.org/10.1007/s10608-011-9397-4

Cowden Hindash, A. H., \& Rottenberg, J. (2017). Turning quickly on myself: Automatic interpretation biases in dysphoria are self-referent. Cognition and Emotion, 31(2), 395402. https://doi.org/10.1080/02699931.2015.1105792

Cristea, I. A., Kok, R. N., \& Cuijpers, P. (2015). Efficacy of cognitive bias modification interventions in anxiety and depression: Meta-analysis. British Journal of Psychiatry, 
206(1), 7-16. https://doi.org/10.1192/bjp.bp.114.146761

D’Avanzato, C. M. (2013). Emotion Regulation in Depression: Investigating Mechanisms Underlying Reappraisal. Dissertation Abstracts International, 75, 1-118.

Dickson, D. A. (2015). Investigating the role of cognitive biases as a risk factor for depression (Dissertation Abstracts International). Dissertation Abstracts International: Section B: The Sciences and Engineering.

Dohr, K. B., Rush, A. J., \& Bernstein, I. H. (1989). Cognitive biases and depression. Journal of Abnormal Psychology, 98(3), 263-267. https://doi.org/10.1037/0021-843X.98.3.263

Downs, S. H., \& Black, N. (1998). The feasibility of creating a checklist for the assessment of the methodological quality both of randomised and non-randomised studies of health care interventions. Journal of Epidemiology and Community Health, 52(6), 377-384. https://doi.org/10.1136/jech.52.6.377

Dugas, M. J., Hedayati, M., Karavidas, A., Buhr, K., Francis, K., \& Phillips, N. A. (2005). Intolerance of uncertainty and information processing: Evidence of biased recall and interpretations. Cognitive Therapy and Research, 29(1), 57-70. https://doi.org/10.1007/s10608-005-1648-9

Duval, S., \& Tweedie, R. (2000). Trim and fill: A simple funnel-plot-based method of testing and adjusting for publication bias in meta-analysis. Biometrics, 56(June), 455-463. https://doi.org/10.1111/j.0006-341x.2000.00455.x

Everaert, J., Duyck, W., \& Koster, E. H. W. (2014). Attention, interpretation, and memory biases in subclinical depression: A proof-of-principle test of the combined cognitive biases hypothesis. Emotion, 14(2), 331-340. https://doi.org/10.1037/a0035250

Everaert, J., Grahek, I., Duyck, W., Buelens, J., Van den Bergh, N., \& Koster, E. H. W. E. H. W. (2016). Mapping the interplay among cognitive biases, emotion regulation, and depressive symptoms. Cognition and Emotion, $0(0), 1-10$. 
https://doi.org/10.1080/02699931.2016.1144561

Everaert, J., Grahek, I., \& Koster, E. H. W. (2017). Individual differences in cognitive control over emotional material modulate cognitive biases linked to depressive symptoms. Cognition and Emotion, 31(4), 736-746. https://doi.org/10.1080/02699931.2016.1144562

Everaert, J., Mogoaşe, C., David, D., \& Koster, E. H. W. (2015). Attention bias modification via single-session dot-probe training: Failures to replicate. Journal of Behavior Therapy and Experimental Psychiatry, 49, 5-12. article.

https://doi.org/10.1016/j.jbtep.2014.10.011

Everaert, J., Tierens, M., Uzieblo, K., \& Koster, E. H. W. (2013). The indirect effect of attention bias on memory via interpretation bias: Evidence for the combined cognitive bias hypothesis in subclinical depression. Cognition \& Emotion, 27(8), 1450-1459. https://doi.org/10.1080/02699931.2013.787972

Faust, M. E., Balota, D. a, Spieler, D. H., \& Ferraro, F. R. (1999). Individual differences in information-processing rate and amount: implications for group differences in response latency. Psychological Bulletin, 125(6), 777-799. https://doi.org/10.1037/00332909.125.6.777

Ferrari, A. J., Somerville, A. J., Baxter, A. J., Norman, R., Patten, S. B., Vos, T., \& Whiteford, H. A. (2013). Global variation in the prevalence and incidence of major depressive disorder: a systematic review of the epidemiological literature. Psychological Medicine, 43(3), 471-81. https://doi.org/10.1017/S0033291712001511

First, M. B., Williams, J. B. W., Karg, R. S., \& Spitzer, R. L. (2015). Structured Clinical Interview for DSM-5. Arlington, VA: American Psychiatric Association.

Foland-Ross, L. C., \& Gotlib, I. H. (2012). Cognitive and neural aspects of information processing in major depressive disorder: An integrative perspective. Frontiers in 
Psychology, 3, 1-17. https://doi.org/10.3389/fpsyg.2012.00489

Frost, R. O., \& MacInnis, D. J. (1983). The cognitive bias questionnaire: Further evidence. Journal of Personality Assessment, 47(2), 173-177. https://doi.org/10.1207/s15327752jpa4702_12

Goggin, L. S. (2011). Affective modulation of the startle reflex is an ineffective methodology to examine depression-linked interpretative biases. Psychology, 2(5), 486-491. https://doi.org/10.4236/psych.2011.25075

Gotlib, I. H., \& Joormann, J. (2010). Cognition and depression: Current status and future directions. Annual Review of Clinical Psychology, 6(1), 285-312. https://doi.org/10.1146/annurev.clinpsy.121208.131305

Greenberg, P. E., Fournier, A.-A., Sisitsky, T., Pike, C. T., \& Kessler, R. C. (2015). The economic burden of adults with major depressive disorder in the United States (2005 and 2010). The Journal of Clinical Psychiatry, 76(2), 155-62.

https://doi.org/10.4088/JCP.14m09298

Gupta, R., \& Kar, B. R. (2008). Interpretive bias: Indicators of cognitive vulnerability to depression. German Journal of Psychiatry, 11(3), 98-102. Retrieved from http://search.ebscohost.com/login.aspx?direct=true\&db=psyh\&AN=2009-02430003\&site=ehost-live\%5Cnrash_cogsci@yahoo.com

Hähnel, A. (2008). Interpretation processes in anxiety and depression. Dissertation Abstracts International.

Halberstadt, L., Haeffel, G. J., Abramson, L. Y., Mukherji, B. R., Metalsky, G. I., \& Dykman, B. M. (2008). Schematic processing: A comparison of clinically depressed, dysphoric, and nondepressed college students. Cognitive Therapy and Research, 32(6), 843-855. https://doi.org/10.1007/s10608-007-9153-y

Hedges, L. V., \& Olkin, I. (1985). Statistical methods for meta-analysis. Orlando, FL: 
Academic Press. https://doi.org/http://doi.org/10.1002/sim.650

Hedlund, S., \& Rude, S. S. (1995). Evidence of latent depressive schemas in formerly depressed individuals. Journal of Abnormal Psychology, 104(3), 517-525. https://doi.org/10.1037/0021-843X.104.3.517

Hertel, P. T., \& El-Messidi, L. (2006). Am I Blue? Depressed Mood and the Consequences of Self-Focus for the Interpretation and Recall of Ambiguous Words. Behavior Therapy, 37(3), 259-268. https://doi.org/10.1016/j.beth.2006.01.003

Hirsch, C. R., Meeten, F., Krahé, C., \& Reeder, C. (2016). Resolving ambiguity in emotional disorders: The nature and role of interpretation biases. Annual Review of Clinical Psychology, 12(1), 281-305. https://doi.org/10.1146/annurev-clinpsy-021815-093436

Holmes, E. A., Lang, T. J., \& Deeprose, C. (2009). Mental imagery and emotion in treatment across disorders: Using the example of depression. Cognitive Behaviour Therapy, 38, 21-28. https://doi.org/10.1080/16506070902980729

Holmes, E. A., Lang, T. J., Moulds, M. L., \& Steele, A. M. (2008). Prospective and positive mental imagery deficits in dysphoria. Behaviour Research and Therapy, 46(8), 976-981. https://doi.org/10.1016/j.brat.2008.04.009

Holmes, E. A., Mathews, A., Dalgleish, T., \& Mackintosh, B. (2006). Positive Interpretation Training: Effects of Mental Imagery Versus Verbal Training on Positive Mood. Behavior Therapy, 37(3), 237-247. https://doi.org/10.1016/j.beth.2006.02.002

Hughes, A., Hirsch, C., Chalder, T., \& Moss-Morris, R. (2016). Attentional and interpretive bias towards illness-related information in chronic fatigue syndrome: A systematic review. British Journal of Health Psychology, 21(4), 741-763. https://doi.org/10.1111/bjhp.12207

Huppert, J. D., Foa, E. B., Furr, J. M., Filip, J. C., \& Mathews, A. (2003). Interpretation bias in social anxiety: A dimensional perspective. Cognitive Therapy and Research, 27(5), 
569-577. https://doi.org/10.1023/A:1026359105456

Ingram, R. E. (1984). Toward an information-processing analysis of depression. Cognitive Therapy and Research, 8(5), 443-477. https://doi.org/10.1007/BF01173284

Ingram, R. E., Miranda, J., \& Segal, Z. V. (1999). Cognitive Vulnerability to Depression. New York, NY: The Guilford Press. https://doi.org/10.1176/appi.ps.51.4.538

Ingram, R. E., \& Siegle, G. J. (2009). Methodological issues in the study of depression. In I. H. Gotlib \& C. L. Hammen (Eds.), Handbook of depression (pp. 60-92). New York: The Guilford Press.

Juang, C., \& Knight, B. G. (2016). Age differences in interpreting ambiguous situations: The effects of content themes and depressed mood. Journals of Gerontology - Series B Psychological Sciences and Social Sciences, 71(6), 1024-1033. https://doi.org/10.1093/geronb/gbv037

Just, N., Abramson, L. Y., \& Alloy, L. B. (2001). Remitted depression studies as tests of the cognitive vulnerability hypotheses of depression onse: A critique and conceptual analysis. Clinical Psychology Review, 21(1), 63-83. https://doi.org/10.1016/S02727358(99)00035-5

Käse, M., Dresler, T., Andreatta, M., Ehlis, A. C., Wolff, B., Kittel-Schneider, S., ... Mühlberger, A. (2013). Is there a negative interpretation bias in depressed patients? An affective startle modulation study. Neuropsychobiology, 67(4), 201-209. https://doi.org/10.1159/000347086

Kessler, R. C., \& Bromet, E. J. (2013). The epidemiology of depression across cultures. Annual Review of Public Health, 34(1), 119-38. https://doi.org/10.1146/annurevpublhealth-031912-114409

Kleim, B., Thörn, H. A., \& Ehlert, U. (2014). Positive interpretation bias predicts well-being in medical interns. Frontiers in Psychology, 5, 1-6. 
https://doi.org/10.3389/fpsyg.2014.00640

Krantz, S., \& Hammen, C. L. (1979). Assessment of cognitive bias in depression. Journal of Abnormal Psychology, 88(6), 611-619. https://doi.org/10.1037/0021-843X.88.6.611

Lambert, J. E., Benight, C. C., Wong, T., \& Johnson, L. E. (2013). Cognitive bias in the interpretation of physiological sensations, coping self-efficacy, and psychological distress after intimate partner violence. Psychological Trauma: Theory, Research, Practice, and Policy, 5(5), 494-500. https://doi.org/10.1037/a0029307

Lang, T. J., Blackwell, S. E., Harmer, C. J., Davison, P., \& Holmes, E. A. (2012). Cognitive bias modification using mental imagery for depression: Developing a novel computerized intervention to change negative thinking styles. European Journal of Personality, 26(2), 145-157. https://doi.org/10.1002/per.855

Lawson, C., \& MacLeod, C. (1999). Depression and the interpretation of ambiguity. Behaviour Research and Therapy, 37(5), 463-474. https://doi.org/10.1016/S00057967(98)00131-4

Lawson, C., MacLeod, C., \& Hammond, G. (2002). Interpretation revealed in the blink of an eye: Depressive bias in the resolution of ambiguity. Journal of Abnormal Psychology, 111(2), 321-328. https://doi.org/10.1037/0021-843X.111.2.321

Lee, J. S., Mathews, A., Shergill, S., \& Yiend, J. (2016). Magnitude of negative interpretation bias depends on severity of depression. Behaviour Research and Therapy, 83, 26-34. https://doi.org/10.1016/j.brat.2016.05.007

Lievaart, M., Heiden, C. van der, Geraerts, E., Colin van der Heiden, M. L., \& Geraerts, E. (2013). Associations between depressive symptoms, rumination, overgeneral autobiographical mmemory and interpretation bias within a clinically depressed sample. Journal of Psychology \& Psychotherapy, 7(4), 0-6. https://doi.org/10.4172/21610487.S7-004 
Lo, H. (2009). Thought suppression as a cognitive vulnerability factor for depression - an fMRI study. Psychiatrie und Psychotherapie. Dissertation Abstracts International.

Mathews, A., \& Macleod, C. M. (2005). Cognitive vulnerability to emotional disorders. Annual Review of Clinical Psychology, 1(1), 167-195. https://doi.org/10.1146/annurev.clinpsy.1.102803.143916

Menne-Lothmann, C., Viechtbauer, W., Höhn, P., Kasanova, Z., Haller, S. P., Drukker, M., ... Lau, J. Y. F. (2014). How to boost positive interpretations? A meta-analysis of the effectiveness of cognitive bias modification for interpretation. PLoS ONE, 9(6), e100925. https://doi.org/10.1371/journal.pone.0100925

Miller, I. W., \& Norman, W. H. (1986). Persistence of depressive cognitions within a subgroup of depressed inpatients. Cognitive Therapy and Research, 10(2), 211-224. https://doi.org/10.1007/BF01173726

Möbius, M., Tendolkar, I., Lohner, V., Baltussen, M., \& Becker, E. S. (2015). Refilling the half-empty glass - Investigating the potential role of the Interpretation Modification Paradigm for Depression (IMP-D). Journal of Behavior Therapy and Experimental Psychiatry, 49(Part A), 37-43. https://doi.org/10.1016/j.jbtep.2015.03.002

Mogg, K., Bradbury, K. E., \& Bradley, B. P. (2006). Interpretation of ambiguous information in clinical depression. Behaviour Research and Therapy, 44(10), 1411-1419. https://doi.org/10.1016/j.brat.2005.10.008

Mor, N., Hertel, P. T., Ngo, T. A., Shachar, T., \& Redak, S. (2014). Interpretation bias characterizes trait rumination. Journal of Behavior Therapy and Experimental Psychiatry, 45(1), 67-73. https://doi.org/10.1016/j.jbtep.2013.08.002

Mor, N., \& Winquist, J. (2002). Self-focused attention and negative affect: a meta-analysis. Psychological Bulletin, 128(4), 638-662. https://doi.org/10.1037/0033-2909.128.4.638 Moser, J. S., Huppert, J. D., Foa, E. B., \& Simons, R. F. (2012). Interpretation of ambiguous 
social scenarios in social phobia and depression: Evidence from event-related brain potentials. Biological Psychology, 89(2), 387-397.

https://doi.org/10.1016/j.biopsycho.2011.12.001

Norman, W. H., Miller, I. W., \& Klee, S. H. (1983). Assessment of cognitive distortion in a clinically depressed population. Cognitive Therapy and Research, 7(2), 133-140. https://doi.org/10.1007/BF01190066

Normansell, K. M., \& Wisco, B. E. (2016). Negative interpretation bias as a mechanism of the relationship between rejection sensitivity and depressive symptoms. Cognition \& Emotion, 9931(May), 1-13. https://doi.org/10.1080/02699931.2016.1185395

Novovic, Z., Mihic, L., Biro, M., \& Tovilovic, S. (2014). Measuring Vulnerability to Depression: The Serbian Scrambled Sentences Test - SSST. Psihologija, 47(1), 33-48. https://doi.org/10.2298/PSI1401033N

Nunn, J. D., Mathews, A., \& Trower, P. (1997). Selective processing of concern-related information in depression. The British Journal of Clinical Psychology / the British Psychological Society, 36 ( Pt 4)(4), 489-503. https://doi.org/10.1111/j.20448260.1997.tb01256.x

Orsini, N., Bottai, M., Higgins, J., \& Buchan, I. (2006). HETEROGI: Stata module to quantify heterogeneity in a meta-analysis. Statistical Software Components. Boston College Department of Economics.

Phillips, W. J., Hine, D. W., \& Bhullar, N. (2012). A Latent profile analysis of implicit and explicit cognitions associated with depression. Cognitive Therapy and Research, 36(5), 458-473. https://doi.org/10.1007/s10608-011-9381-z

Phillips, W. J., Hine, D. W., \& Thorsteinsson, E. B. (2010). Implicit cognition and depression: A meta-analysis. Clinical Psychology Review, 30(6), 691-709. https://doi.org/10.1016/j.cpr.2010.05.002 
Pury, C. L. S. (2002). Information-processing predictors of emotional response to stress. Cognition \& Emotion, 16(1), 667-683. https://doi.org/10.1080/02699930143000400

Riley, R. D., Higgins, J. P. T., \& Deeks, J. J. (2011). Interpretation of random effects metaanalyses. Bmj, 342(7804), d549. https://doi.org/10.1136/bmj.d549

Rohrbacher, H., Blackwell, S. E., Holmes, E. A., \& Reinecke, A. (2014). Optimizing the ingredients for imagery-based interpretation bias modification for depressed mood: Is self-generation more effective than imagination alone? Journal of Affective Disorders, 152-154(1), 212-218. https://doi.org/10.1016/j.jad.2013.09.013

Rohrbacher, H., \& Reinecke, A. (2014). Measuring Change in Depression-Related Interpretation Bias: Development and Validation of a Parallel Ambiguous Scenarios Test. Cognitive Behaviour Therapy, 43(3), 239-250.

https://doi.org/10.1080/16506073.2014.919605

Romero, N., Sanchez, A., \& Vazquez, C. (2014). Memory biases in remitted depression: The role of negative cognitions at explicit and automatic processing levels. Journal of Behavior Therapy and Experimental Psychiatry, 45(1), 128-135. https://doi.org/10.1016/j.jbtep.2013.09.008

Rude, S. S., Covich, J., Jarrold, W., Hedlund, S., \& Zentner, M. (2001). Detecting Depressive Schemata in Vulnerable Individuals: Questionnaires Versus Laboratory Tasks. Cognitive Therapy and Research, 25(1), 103-116. https://doi.org/10.1023/A:1026482917201

Rude, S. S., Durham-Fowler, J. A., Baum, E. S., Rooney, S. B., \& Maestas, K. L. (2010). Self-report and cognitive processing measures of depressive thinking predict subsequent major depressive disorder. Cognitive Therapy and Research, 34(2), 107-115. https://doi.org/10.1007/s10608-009-9237-y

Rude, S. S., Valdez, C. R., Odom, S., \& Ebrahimi, A. (2003). Negative cognitive biases predict subsequent depression. Cognitive Therapy and Research, 27(4), 415-429. 
https://doi.org/http://dx.doi.org/10.1023/A:1025472413805

Sanchez, A., Everaert, J., De Putter, L. M. S., Mueller, S. C., \& Koster, E. H. W. (2015). Life is ... great! Emotional attention during instructed and uninstructed ambiguity resolution in relation to depressive symptoms. Biological Psychology, 109(MAY), 67-72. https://doi.org/10.1016/j.biopsycho.2015.04.007

Sanchez, A., Everaert, J., \& Koster, E. H. W. (2016). Attention training through gazecontingent feedback: Effects on reappraisal and negative emotions. Emotion, 16(7), 1074-1085. https://doi.org/10.1037/emo0000198

Sears, C. R., Suzie Bisson, M. A., \& Nielsen, K. E. (2011). Dysphoria and the immediate interpretation of ambiguity: Evidence for a negative interpretive bias in error rates but not response latencies. Cognitive Therapy and Research, 35(5), 469-476. https://doi.org/10.1007/s10608-010-9314-2

Seeds, P. A. (2012). Interpretive bias in the context of life stress and depression: An examination of stress generation and diathesis-stress models. Dissertation Abstracts International.

Shane, M. S., \& Peterson, J. B. (2007). An evaluation of early and late stage attentional processing of positive and negative information in dysphoria. Cognition \& Emotion, 21(4), 789-815. https://doi.org/10.1080/02699930600843197

Starr, S., \& Moulds, M. L. (2006). The role of negative interpretations of intrusive memories in depression. Journal of Affective Disorders, 93(1-3), 125-132. https://doi.org/10.1016/j.jad.2006.03.001

Sterne, J. A. C., Becker, B. J., \& Egger, M. (2006). The Funnel Plot. In Publication Bias in Meta-Analysis: Prevention, Assessment and Adjustments (pp. 73-98). Chichester, UK: John Wiley \& Sons, Ltd. https://doi.org/10.1002/0470870168.ch5

Teachman, B. A., Joormann, J., Steinman, S. A., \& Gotlib, I. H. (2012). Automaticity in 
anxiety disorders and major depressive disorder. Clinical Psychology Review (Vol. 32).

United States: Elsevier B.V. https://doi.org/10.1016/j.cpr.2012.06.004

Teasdale, J. D., Lloyd, C. a, \& Hutton, J. M. (1998). Depressive thinking and dysfunctional schematic mental models. The British Journal of Clinical Psychology / the British Psychological Society, 37 ( Pt 3), 247-257.

Teasdale, J. D., Taylor, M. J., Cooper, Z., Hayhurst, H., \& Paykel, E. S. (1995). Depressive thinking: shifts in construct accessibility or in schematic mental models? Journal of Abnormal Psychology, 104(3), 500-507. https://doi.org/10.1037/0021-843X.104.3.500

Torkan, H., Blackwell, S. E., Holmes, E. A., Kalantari, M., Neshat-Doost, H. T., Maroufi, M., \& Talebi, H. (2014). Positive imagery cognitive bias modification in treatment-seeking patients with major depression in Iran: A pilot study. Cognitive Therapy and Research, 38(2), 132-145. https://doi.org/10.1007/s10608-014-9598-8

Van der Does, W. (2005). Thought suppression and cognitive vulnerability to depression. British Journal of Clinical Psychology, 44(1), 1-14. https://doi.org/10.1348/014466504x19442

Voncken, M. J., Bögels, S. M., Peeters, F., Bogels, S. M., \& Peeters, F. (2007). Specificity of interpretation and judgemental biases in social phobia versus depression. Psychology and Psychotherapy, 80(3), 443-453. https://doi.org/10.1348/147608306X161890

Watkins, E. R., \& Moulds, M. (2007). Revealing negative thinking in recovered major depression: A preliminary investigation. Behaviour Research and Therapy, 45(12), 3069-3076. https://doi.org/10.1016/j.brat.2007.05.001

Wenzlaff, R. M., \& Bates, D. E. (1998). Unmasking a cognitive vulnerability to depression: how lapses in mental control reveal depressive thinking. Journal of Personality and Social Psychology, 75(6), 1559-1571. https://doi.org/10.1037/0022-3514.75.6.1559 WHO. (2012). Depression, a global public health concern. WHO Department of Mental 
Health and Substance Abuse. https://doi.org/10.1007/978-3-642-11688-9_20

Williams, A. D., Blackwell, S. E., Mackenzie, A., Holmes, E. A., \& Andrews, G. (2013). Combining imagination and reason in the treatment of depression: A randomized controlled trial of internet-based cognitive-bias modification and internet-CBT for depression. Journal of Consulting and Clinical Psychology, 81(5), 793-799. https://doi.org/10.1037/a0033247

Williams, A. D., O’Moore, K., Blackwell, S. E., Smith, J., Holmes, E. A., \& Andrews, G. (2015). Positive imagery cognitive bias modification (CBM) and internet-based cognitive behavioral therapy (iCBT): A randomized controlled trial. Journal of Affective Disorders, 178(10), 131-141. https://doi.org/10.1016/j.jad.2015.02.026

Wisco, B. E. (2009). Depressive cognition: Self-reference and depth of processing. Clinical Psychology Review, 29(4), 382-392. article. https://doi.org/10.1016/j.cpr.2009.03.003

Wisco, B. E., \& Nolen-Hoeksema, S. (2010). Interpretation bias and depressive symptoms: The role of self-relevance. Behaviour Research and Therapy, 48(11), 1113-1122. https://doi.org/10.1016/j.brat.2010.08.004

Wisco, B. E., \& Nolen-Hoeksema, S. (2011). Effect of visual perspective on memory and interpretation in dysphoria. Behaviour Research and Therapy, 49(6-7), 406-412. https://doi.org/10.1016/j.brat.2011.03.012

Yiend, J., Lee, J. S., Tekes, S., Atkins, L., Mathews, A., Vrinten, M., ... Shergill, S. (2014). Modifying interpretation in a clinically depressed sample using "cognitive bias modification-errors": A double blind randomised controlled trial. Cognitive Therapy and Research, 38(2), 146-159. https://doi.org/10.1007/s10608-013-9571-y

Zimmerman, M., Sheeran, T., \& Young, D. (2004). The Diagnostic Inventory for Depression: A self-report scale to diagnose DSM-IV major depressive disorder. Journal of Clinical Psychology, 60(1), 87-110. https://doi.org/10.1002/jclp.10207 


\section{Appendix S1: Methodological Quality Checklist}

1. Is the hypothesis, aim, objective of the study clearly described? The hypotheses, aims, and objectives must be explicitly formulated. Scoring: $1=$ YES, $0=$ NO.

2. Are all primary outcomes to be measured clearly described in the Introduction or Methods section? If the main outcomes are first mentioned in the results section, the answer should be no. If all primary outcomes are described in the Introduction, the answer is yes. Scoring: $1=$ YES, $0=\mathrm{NO}$.

3. Are the characteristics of the participants included in the study clearly described? For studies involving clinical samples, the inclusion and exclusion criteria (in terms of age, sex, diagnosis) should be given as well as the definition and the source for the control participants should be provided. For studies involving nonclinical samples, an operational definition of dysphoric depressive state should be provided. For all studies, demographic information should be provided (age, sex) as well as depressive symptom severity levels for each group (categorical study designs) or the total sample (dimensional study designs). Scoring: $1=$ YES, $0=\mathrm{NO}$.

4. Were the subjects asked to participate in the study representative of the entire population from which they were recruited? The study must identify the source population for patients and describe how the patients were selected. Scoring: $1=\mathrm{YES}, 0=\mathrm{NO}, 0=$ Unable to determine.

5. Were those subjects who were prepared to participate representative of the entire population from which they were recruited? The proportion of those asked who agreed should be stated. Scoring: $1=$ YES, $0=\mathrm{NO}, 0=$ Unable to determine.

6. Were the participants recruited from the same population? Participants should be selected from the same population. For example, all patients should be recruited from the sample 
hospital, undergraduate students should be from the same university. Scoring: 1=YES, $0=\mathrm{NO}, 0=$ Unable to determine.

7. Were study participants recruited over the same time? Participants should have been recruited within a specified time window. Scoring: $1=$ YES, $0=\mathrm{NO}, 0=$ Unable to determine. For a study which does not specify the time period over which patients were recruited, the question should be answered as unable to determine. Studies must be $<3$ years for yes, if $>3$ years then no.

8. Are the tasks and measures clearly described? The tasks and measures should be explicitly described with examples of the stimulus materials used. Scoring: 1=YES, $0=$ NO.

9. Were the main outcome measures used valid and reliable? The validity and reliability of the task and measures should be proved by referring to relevant prior work or by providing data supporting the use of the task to measure the key constructs (interpretation bias, depression). All primary outcomes need to be valid and reliable for yes. Scoring: 1=YES, $0=\mathrm{NO}, 0=$ Unable to determine.

10. Was the participants' engagement with the experimental task(s) assessed? Did the study report checks for outliers, RTs from errors discarded, and/or exclusion of individuals not conforming to the task instructions? Scoring: $1=$ YES, $0=\mathrm{NO}, 0=$ Unable to determine.

11. Did the study consider principal confounders (e.g., such as race, sex, marital status/family, age, SES (income or class), education) and was there adequate adjustment for confounding in the analyses from which the main findings were drawn? Studies need to examine potential group differences on potentially confounding variables (when utilizing a categorical design) or assess correlations with depression severity and potentially confounding variables (when utilizing a dimensional design). If the effect of the main confounders was not investigated or no adjustment was made in the final analyses the question should be answered as no. If no significant difference between groups or no 
relation between confounder and key variable, then YES. Scoring: 2=YES, $1=$ PARTIALLY $0=\mathrm{NO}, 0=$ Unable to determine.

12. Were the statistical tests used to assess the main outcomes appropriate? The statistical techniques used must be appropriate to the data. If no tests done but it would have been appropriate to do then the item should be scored as no. Scoring: $1=$ YES, $0=\mathrm{NO}, 0=$ Unable to determine.

13. Are the main findings of the study clearly described? Simple outcome data (including denominators and numerators) should be reported for all major findings so that the reader can check the major analyses and conclusions. Scoring: 1=YES, $0=\mathrm{NO}$.

14. Does the study provide estimates of the random variability in the data for the main outcomes? In non-normally distributed data the inter-quartile range of results should be reported. In normally distributed data the standard error, standard deviation or confidence intervals should be reported. Scoring: $1=\mathrm{YES}, 0=\mathrm{NO}$.

15. Have actual probability values been reported (e.g. 0.035 rather than $<0.05$ ) for the main outcomes except where the probability value is less than 0.001 ? Scoring: $1=\mathrm{YES}, 0=\mathrm{NO}$.

16. Were withdrawals and drop-outs reported in terms of numbers and/or reasons? Scoring: $1=$ YES, $0=\mathrm{NO}$.

17. If any of the results of the study were based on "data dredging", was this made clear? Any analyses that had not been planned at the outset of the study should be clearly indicated. Retrospective analyses should be rated as 'no', prospective as 'yes'. Scoring: 1=YES, $0=\mathrm{NO}, 0=$ Unable to determine.

18. Did the study have sufficient power to detect a clinically important effect where the probability value for a difference being due to chance $<5 \%$ ? The study needs to report a power analysis (calculating the required sample size given an effect size and desired power). Scoring: $1=$ YES, $0=\mathrm{NO}$. 


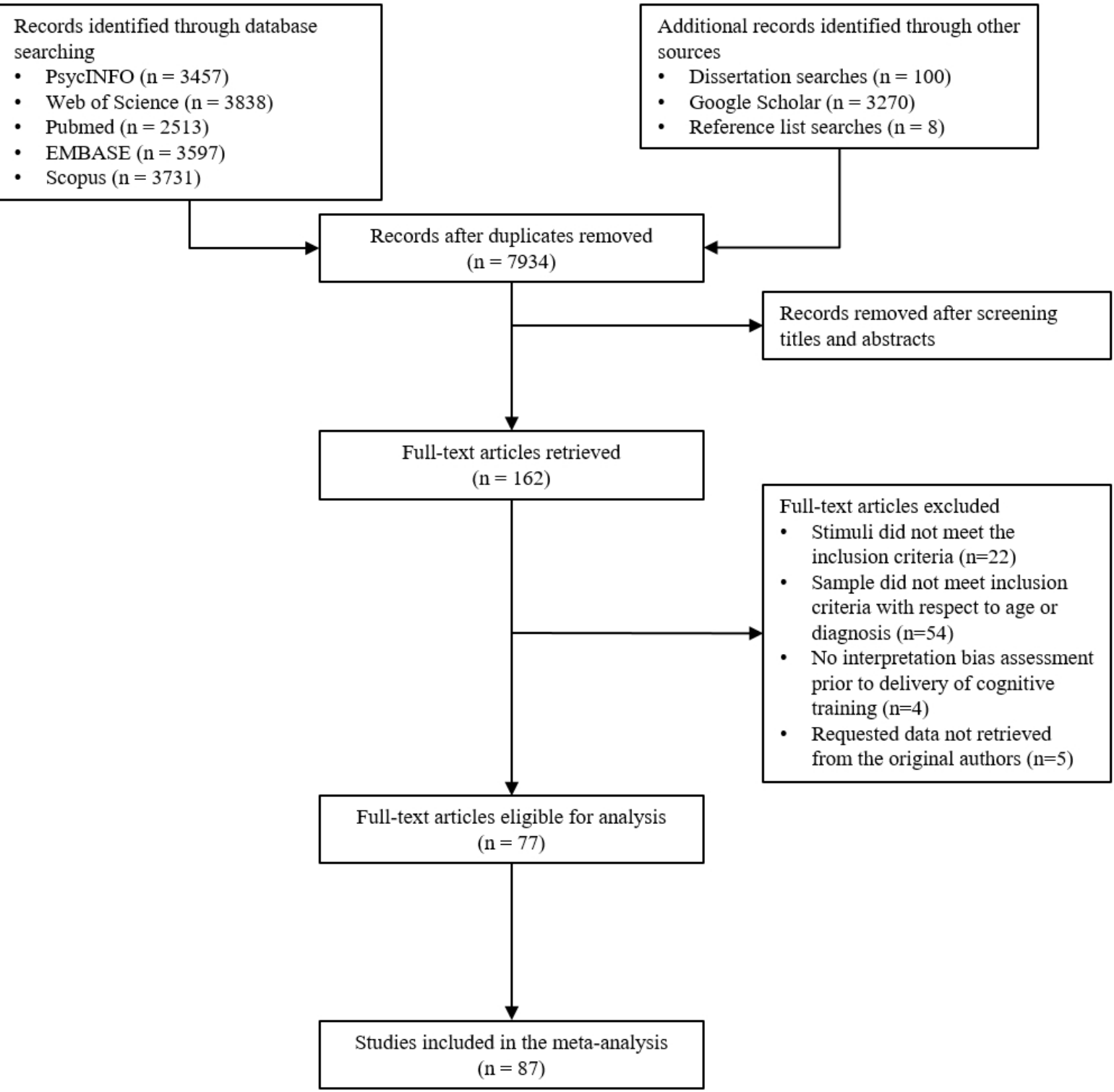

Figure 1. PRISMA flow chart depicting the study selection process. 
Bearc ena1, 2016

Beevers et ai, 2009

Belll 2013

Berva ex al. 2011.

Basons sears 2007

Basens sean. 2007 it

Bwons sean. 20072

Backweil s roines, 2010

Bascieli et al. 2015

Banej et al. 19501

Baneje al, 1950

sonver. 2005

Bower a Marewa. 1900

Caner ef at 19es

Cooger $\Delta$ Wase. 2015

Cousen mincaun s Amit. 2012

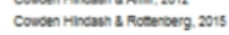

DAarzato ats

Dioxinuon 2015

Dugat es at 2005

Beroert ex ac, 2013

Eernent at al, 2014

Eersenter a., 2015.1

Exerent a 2. 2015.

Eerserter al 2016

Froes 8 vacimic, 1005

Gogginerat 2011

Gupta 8 Kar, 2019

rabentact exa. 2000

Mabentad es al. 2009

reoven s Fude, 1905

Hoimes ef al. 2009

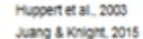

Jang s knigrt 2015

comm ex. 2014

Karte s rammen, 1979

Krarte s rammen 19792

Lambert ex al, 2013

Lungexic. 2012

Letera. 2016

Levast et al. 2013

Leasat 10.2009

Miner 8 Norman, 1968.1

Mines a Norman, 19562

Moous et al. 2015.1

Moovis ea al. 20152

Mogg eal. 2006

Morex. 20141

Moretal. 20142

Moser et at, 2012

Norman eac. 1900

Noovic ex a1, 2014

Numet al, 1997

Pun. 2002

Fonnacher a Fenecie 2014

Monroverer exa. 2014

Fonero ex al. 2014

Ruote et al., 2001

Fuoe et al, 2002

Rude et al, 2003

Ruoteraic. 2010

Sunchez en al, 2015

Seart ex al. 2011

$\operatorname{sen} 2012$

Star 4 Movios 2006

Teavale exa. 1995

Teasoale of al. 1998

Tonan et a1. 2014

Van oer Does. 2005

Voncien ex al, 2007

Wasins 8 Moules. 2007

Werzions Bumb. 1990

Werziars Esserberg. 200

willome ex al, 2013

Wichers a a 2015

Wacos s noessera. 20102

Wisoo 8 Hoestera. 2011

nevo eta. 2013

Pooled
Hedges's Lower Upper

limit limit p-Value

$\begin{array}{llll}0.101 & -0.399 & 0.602 & 0.602\end{array}$

$\begin{array}{llll}0.434 & 0.053 & 0.516 & 0.028 \\ 1.130 & 0.351 & 1.350 & 0.003\end{array}$

$0.991 \quad 0.645 \quad 1.386 \quad 0000$

$\begin{array}{llll}1.385 & 0.590 & 2180 & 0.001 \\ 0.000 & -0.507 & 0.507 & 1000\end{array}$

$\begin{array}{llll}0.000 & -0.507 & 0.507 & 1000\end{array}$

$0.491 \quad 0.002 \quad 0.950 \quad 0.049$

$141 \quad 0790 \quad 2093 \quad 0000$

1.149 orm $1.520 \quad 0000$

$\begin{array}{lllll}0.537 & 0.262 & 0.792 & 0000\end{array}$

$0.978 \quad 0.74 \quad 1211 \quad 0000$

$\begin{array}{llll}1603 & 0.907 & 2250 & 0.000\end{array}$

$\begin{array}{llll}0.922 & 0.106 & 1.797 & 0.027\end{array}$

$\begin{array}{llll}0.673 & 0.358 & 0.957 & 0.000\end{array}$

$0.765 \quad 0.454 \quad 1.053 \quad 0.000$

$\begin{array}{llll}1651 & 0.809 & 2614 & 0.000\end{array}$

$\begin{array}{llll}0.594 & 0.209 & 0979 & 0002\end{array}$

$\begin{array}{llll}0.326 & -0.801 & 0.153 & 0.183 \\ 0.500 & 0.155 & 1.450 & 0.015\end{array}$

$\begin{array}{llll}0.941 & 0.323 & 1.559 & 0.003\end{array}$

$\begin{array}{llll}0.672 & 0.350 & 1.014 & 00000\end{array}$

$\begin{array}{llll}1.320 & 0.784 & 1.085 & 00000 \\ 1725 & 1012 & 2.08 & 0.000\end{array}$

$\begin{array}{llll}1.725 & 1.042 & 2008 & 0000\end{array}$

$\begin{array}{llll}0.800 & 0.169 & 1.591 & 0.015 \\ 0.901 & 0.179 & 150 & 0.914\end{array}$

$\begin{array}{llll}0.851 & 0.179 & 1.58 & 0.014 \\ 1008 & 0.575 & 1.499 & 0.000\end{array}$

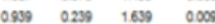

$\begin{array}{llll}-0.357 & -0.930 & 0.216 & 0.222\end{array}$

$\begin{array}{llll}1.406 & 0.44 & 2367 & 0.004\end{array}$

$0.700 \quad 0.205 \quad 1.204 \quad 0.002$

$0.511 \quad 0.294$ 0.728 0000

$\begin{array}{llll}1.119 & 0.390 & 1800 & 0002\end{array}$

$0021 \quad-0.620 \quad 0.662 \quad 0.945$

$\begin{array}{lllll}0.250 & -0.227 & 0.663 & 0.334\end{array}$

$0.452 \quad 0.050 \quad 0.355 \quad 0.028$

0.221 - 0.041 0.50 0074

$\begin{array}{llll}0.072 & -0.355 & 0.725 & 0.850 \\ 1135 & 0.464 & 1306 & 0.001\end{array}$

$\begin{array}{llll}0.251 & -0.006 & 0.531 & 0.057\end{array}$

$\begin{array}{llll}0.559 & 0.363 & 0.814 & 0.000\end{array}$

$\begin{array}{llll}1.385 & 0.716 & 2050 & 0.000\end{array}$

$\begin{array}{llll}1.07 & 0.169 & 1.984 & 0.020\end{array}$

$\begin{array}{llll}-0340 & -1.024 & 0.343 & 0.320\end{array}$

$0.401 \quad-0.092 \quad 0.093 \quad 0.111$

$\begin{array}{llll}1.369 & 0.532 & 2246 & 0.001 \\ 0.592 & -0.050 & 1215 & 0.062\end{array}$

$\begin{array}{llll}0.132 & -0.368 & 0.652 & 0604\end{array}$

$\begin{array}{llll}0.409 & -0.256 & 1.114 & 0.255\end{array}$

$\begin{array}{llll}-0.045 & -0.495 & 0.056 & 0.866\end{array}$

$\begin{array}{llll}0.225 & -0.176 & 0.629 & 0.270\end{array}$

$0.078-0.131 \quad 1.053 \quad 0.124$

$\begin{array}{llll}0.218 & -0.374 & 0.009 & 0.671\end{array}$

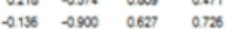

$\begin{array}{llll}-0.156 & -0.900 & 0.627 & 0.726\end{array}$

$\begin{array}{llll}0.960 & 0.358 & 1.522 & 0.001\end{array}$

$\begin{array}{llll}1.202 & 1.100 & 1.225 & 0.000\end{array}$

$\begin{array}{llll}1.190 & 0.502 & 1.797 & 0.000 \\ 1.596 & 1252 & 1819 & 0.000\end{array}$

$\begin{array}{llll}1.536 & 1.252 & 1.810 & 0.000 \\ 0.459 & 0.14 & 1312 & 0.245\end{array}$

$\begin{array}{llll}0.459 & -0.314 & 1.252 & 0.245 \\ 1121 & 0.750 & 1.451 & 0.000\end{array}$

$\begin{array}{llll}1.121 & 0.750 & 1.461 & 0.000 \\ 0.10 & 0.285 & 1.95 & 0.007\end{array}$

$\begin{array}{llll}1.810 & 0.228 & 1.395 & 0009 \\ 0.593 & 0115 & 1071 & 0015\end{array}$

$\begin{array}{lllll}1118 & 0.349 & 138 & 0004\end{array}$

$0.893 \quad 0.656 \quad 1.130 \quad 0000$

$\begin{array}{llll}0.917 & 0.457 & 1.397 & 0.000\end{array}$

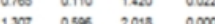

$1451 \quad 0652 \quad 2300 \quad 0000$

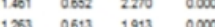

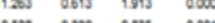

$\begin{array}{llll}0.528 & 0.250 & 0.56 & 0.001 \\ 0.969 & 0.43 & 1.504 & 0.000\end{array}$

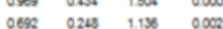

$\begin{array}{llll}0.652 & 0.248 & 1.158 & 0002 \\ 0.933 & 0.050 & 0737 & 0025\end{array}$

$\begin{array}{lllll}0.063 & -0.050 & 1.317 & 0.061\end{array}$

$\begin{array}{llll}0.136 & -0.437 & 0.710 & 0642 \\ 0.373 & -0159 & 0.14 & 0.167\end{array}$

0.378 - 2159 0914 0.167

$\begin{array}{llll}1.397 & 0.48 & 2366 & 0.004 \\ 0.512 & 0.004 & 1000 & 0045\end{array}$

$\begin{array}{llll}0.512 & 0.004 & 1000 & 0.045 \\ 0956 & 0497 & 1596 & 0000\end{array}$

$\begin{array}{llll}0.956 & 0.437 & 1.556 & 0.000\end{array}$

$0.769 \quad 0.278 \quad 1261 \quad 0002$

$\begin{array}{llll}0637 & 0234 & 1041 & 0002\end{array}$

$\begin{array}{llll}1.051 & 0.606 & 1.656 & 0.000 \\ 1090 & 0.652 & 1543 & 0.000\end{array}$

$\begin{array}{llll}10000 & 0662 & 1.518 & 0000 \\ 1601 & 0762 & 2459 & 0000\end{array}$

$\begin{array}{llll}1.601 & 0762 & 2.159 & 0.000 \\ 0.754 & 0.708 & 0.300 & 0.000\end{array}$

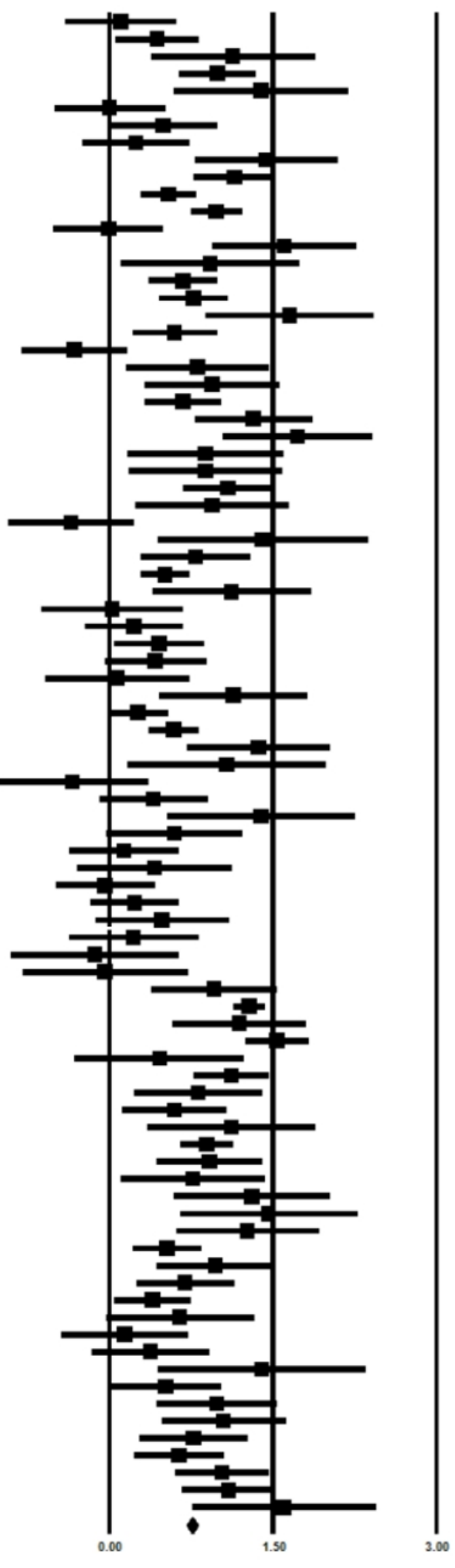

Favours Benign IB

Favours Malign I8

Figure 2. Forest plot. 


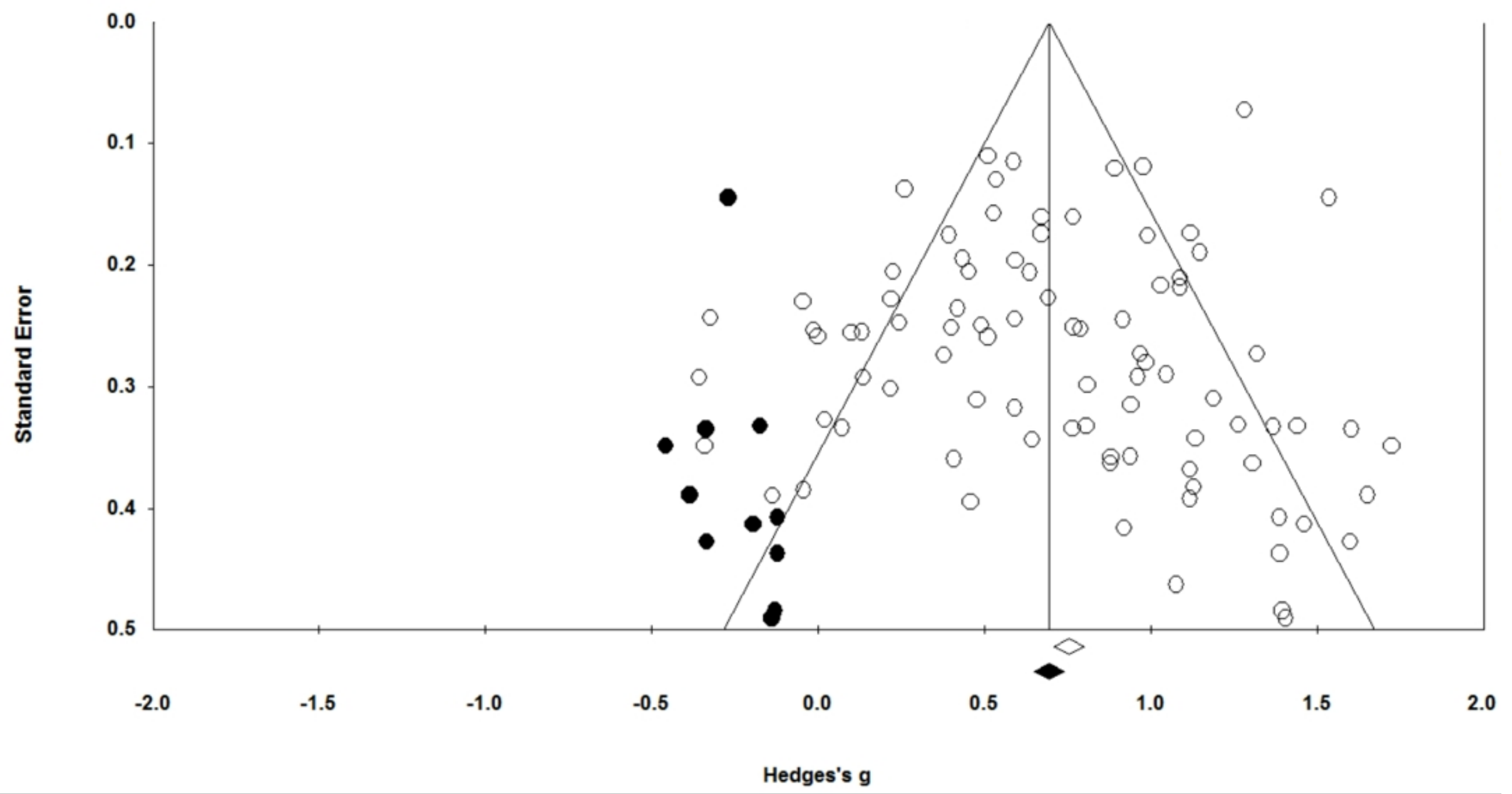

Figure 3. Funnel plot. 
Table 1. Characteristics of the studies included.

\begin{tabular}{|c|c|c|c|c|c|c|c|c|c|c|}
\hline$\stackrel{\bar{g}}{\dot{E}}$ & 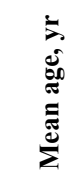 & 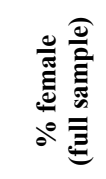 & 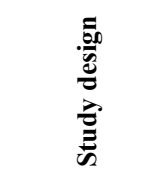 & 苞总 & 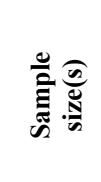 & 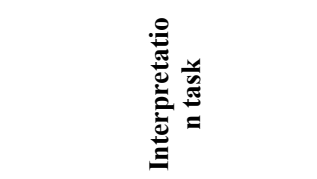 & 莺 & 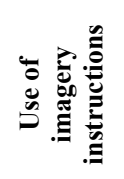 & 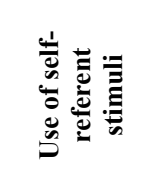 & 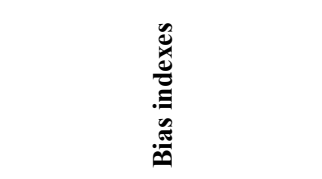 \\
\hline 1. Beard et al., 2016 & 32.28 & 56.90 & Dimensional & $\mathrm{CD}, \mathrm{UDS}$ & 65 & WSAP & $\begin{array}{l}\text { Direct, } \\
\text { Indirect }\end{array}$ & No & Yes & Absolute, Relative \\
\hline 2. Beevers et al., 2009 & 21.62 & 59 & Categorical & UDS, ND & 107 & $\begin{array}{l}\text { Ambiguous face } \\
\text { identification task }\end{array}$ & Direct & No & No & Relative \\
\hline 3. $\quad$ Belli, 2013, u.p.1 & 20.25 & 57.5 & Dimensional & UDS, ND & 38 & ASSIQ & Direct & No & Yes & Absolute negative \\
\hline 4. Berna et al., 2011.1 & 22.49 & 65.38 & $\begin{array}{l}\text { Categorical, } \\
\text { Dimensional }\end{array}$ & UDS, ND & 144 & AST & Direct & Yes & Yes & Relative \\
\hline 5. Berna et al., 2011.2 & 22.22 & 69.44 & $\begin{array}{l}\text { Categorical, } \\
\text { Dimensional }\end{array}$ & UDS, ND & 33 & AST & Direct & Yes & Yes & $\begin{array}{l}\text { Absolute negative, } \\
\text { Absolute positive, Relative }\end{array}$ \\
\hline 6. Bisson \& Sears, 2007.1a & 21.3 & 100.00 & Categorical & UDS, ND & 61 & Semantic priming task & Indirect & No & No & $\begin{array}{l}\text { Absolute positive, } \\
\text { Absolute negative }\end{array}$ \\
\hline 7. Bisson \& Sears, 2007.1b & 21.3 & 100.00 & Categorical & UDS, ND & 65 & Semantic priming task & Indirect & No & No & $\begin{array}{l}\text { Absolute positive, } \\
\text { Absolute negative }\end{array}$ \\
\hline 8. Bisson \& Sears, 2007.2 & 20.7 & 100.00 & Categorical & UDS, ND & 86 & Semantic priming task & Indirect & No & No & $\begin{array}{l}\text { Absolute positive, } \\
\text { Absolute negative }\end{array}$ \\
\hline 9. $\quad$ Blackwell \& Holmes, 2010 & 37.7 & 71.42 & Dimensional & $\mathrm{CD}$ & 7 & SST & Direct & No & Yes & Relative \\
\hline 10. Blackwell et al. 2015 & 35.46 & 68.66 & Dimensional & $\mathrm{CD}$ & 150 & SST & Direct & No & Yes & Relative \\
\hline 11. Blaney et al., 1980.1 & - & 42.90 & Dimensional & UDS, ND & 255 & CBQ & Direct & Yes & No & Absolute negative \\
\hline 12. Blaney et al., 1980.2 & - & 49.47 & Dimensional & UDS, ND & 351 & CBQ & Direct & Yes & No & Absolute negative \\
\hline 13. Bos, 2005 , u.p. .2 & 44.00 & 66.23 & Categorical & $\mathrm{RD}, \mathrm{ND}$ & 77 & $\begin{array}{l}\text { Ambiguous face } \\
\text { identification task }\end{array}$ & Indirect & No & No & Relative \\
\hline 14. Bowler et al., 2012 & 22.7 & 68.25 & Dimensional & UDS, ND & 63 & SST & Direct & No & Yes & $\begin{array}{l}\text { Relative, Absolute } \\
\text { negative }\end{array}$ \\
\hline 15. Butler \& Mathews, 1983 & 31.8 & 66.66 & Categorical & $\mathrm{CD}, \mathrm{ND}$ & 24 & Interpretation ranking task & Direct & No & Yes & Absolute negative \\
\hline 16. Carver et al., 1985 & - & - & Dimensional & UDS, ND & 175 & CBQ & Direct & Yes & No & Absolute negative \\
\hline 17. Cooper \& Wade, 2015 & 19.24 & 100 & Dimensional & UDS, ND & 180 & AST & Direct & Yes & Yes & Relative \\
\hline $\begin{array}{l}\text { 18. Cowden Hindash \& Amir, } \\
2012\end{array}$ & 18.68 & 46.00 & $\begin{array}{l}\text { Categorical, } \\
\text { Dimensional }\end{array}$ & UDS, ND & 50 & WSAP & $\begin{array}{l}\text { Direct, } \\
\text { Indirect }\end{array}$ & No & Yes & $\begin{array}{l}\text { Absolute positive, } \\
\text { Absolute negative }\end{array}$ \\
\hline
\end{tabular}


Table 1. (continued).

\begin{tabular}{|c|c|c|c|c|c|c|c|c|c|c|}
\hline$\stackrel{\bar{g}}{\underline{E}}$ & 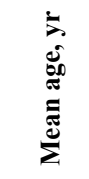 & 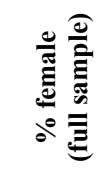 & 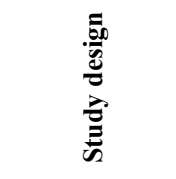 & 氖 邑 & 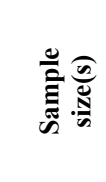 & 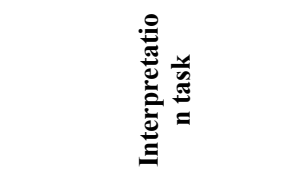 & 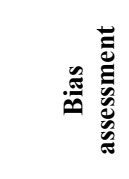 & 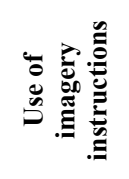 & 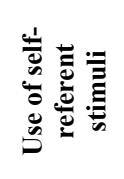 & 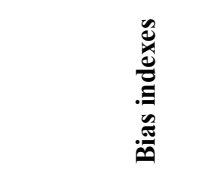 \\
\hline 19. Cowden Hindash \& Rottenberg, 2015 & 21.36 & 64.4 & Categorical & UDS, ND & 115 & WSAP & $\begin{array}{l}\text { Direct, } \\
\text { Indirect }\end{array}$ & No & Yes & $\begin{array}{l}\text { Absolute positive, } \\
\text { Absolute negative }\end{array}$ \\
\hline 20. D'Avanzato, 2013, u.p. & 38.7 & 56.7 & Categorical & $\mathrm{CD}, \mathrm{ND}$ & 67 & Homonym task & Direct & No & No & Absolute negative \\
\hline 21. Dohr et al., 1989 & 43.46 & 56.30 & Categorical & $\mathrm{CD}, \mathrm{RD}, \mathrm{ND}$ & 44 & IEM & Direct & No & Yes & Relative \\
\hline 22. Dickson, 2015, u.p. & 20.26 & 68.4 & Categorical & $\mathrm{RD}, \mathrm{ND}$ & 38 & SST & Direct & No & Yes & Relative \\
\hline 23. Dugas et al., 2005.2 & 22.5 & 77.02 & Dimensional & UDS, ND & 148 & AUSD & Direct & No & Yes & Relative \\
\hline 24. Everaert et al. 2013 & 19.79 & 87.50 & $\begin{array}{l}\text { Categorical, } \\
\text { Dimensional }\end{array}$ & UDS, ND & 64 & SST & Direct & No & Yes & Relative \\
\hline 25. Everaert et al. 2014 & 20.31 & 87.32 & $\begin{array}{l}\text { Categorical, } \\
\text { Dimensional }\end{array}$ & UDS, ND & 44 & SST & Direct & No & Yes & Relative \\
\hline 26. Everaert et al., 2015.2a & 19.31 & 63.15 & Dimensional & UDS, ND & 38 & SST & Direct & No & Yes & Relative \\
\hline 27. Everaert et al., 2015.2b & 18.81 & 91.89 & Dimensional & UDS, ND & 39 & SST & Direct & No & Yes & Relative \\
\hline 28. Everaert et al., 2016 & 21.84 & 90.17 & Dimensional & UDS, ND & 119 & SST & Direct & No & Yes & Relative \\
\hline 29. Frost \&Maclnnis, 1983 & - & 100.00 & Dimensional & UDS, ND & 40 & $\mathrm{CBQ}$ & Direct & Yes & No & Absolute negative \\
\hline 30. Goggin et al. 2011 & 39.95 & 60.00 & Categorical & $\mathrm{CD}, \mathrm{ND}$ & 46 & $\begin{array}{l}\text { Affective startle } \\
\text { modulation }\end{array}$ & Indirect & Yes & No & Absolute negative \\
\hline 31. Gupta \& Kar, 2008 & - & - & Categorical & $\mathrm{CD}, \mathrm{RD}, \mathrm{ND}$ & 30 & CBQ & Direct & Yes & No & Absolute \\
\hline 32. Hähnel, 2008, u.p.2 & 22.45 & 100 & Categorical & $\mathrm{CD}, \mathrm{ND}$ & 84 & $\begin{array}{l}\text { IQSD, Semantic priming } \\
\text { task }\end{array}$ & $\begin{array}{l}\text { Direct, } \\
\text { Indirect }\end{array}$ & No, Yes & No, Yes & Absolute negative \\
\hline 33. Halberstadt et al., 2008 & - & 60.33 & Categorical & UDS, CD, ND & 1173 & RIT & Direct & Yes & Yes & $\begin{array}{l}\text { Absolute positive, } \\
\text { Absolute negative }\end{array}$ \\
\hline 34. Hedlund\& Rude, 1995 & 32.40 & 75.47 & Categorical & $\mathrm{CD}, \mathrm{RD}, \mathrm{ND}$ & 53 & SST & Direct & No & Yes & Absolute negative \\
\hline 35. Hertel \& El-Messidi, 2006.1 & - & 52.77 & Categorical & UDS, ND & 36 & Homonym task & Direct & No & No, Yes & Absolute negative \\
\hline 36. Holmes et al., 2008 & 22.60 & 61.11 & $\begin{array}{l}\text { Categorical, } \\
\text { Dimensional }\end{array}$ & UDS, ND & 78 & Homonym task & Direct & Yes & No & $\begin{array}{l}\text { Absolute positive, } \\
\text { Absolute negative }\end{array}$ \\
\hline
\end{tabular}


Table 1. (continued).

\begin{tabular}{|c|c|c|c|c|c|c|c|c|c|c|}
\hline$\stackrel{\bar{g}}{\dot{E}}$ & 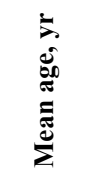 & 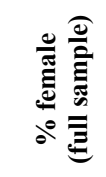 & 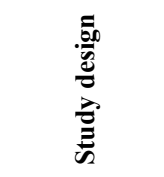 & 占 兰 & 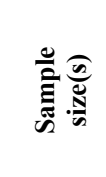 & 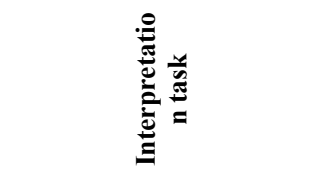 & 章 & 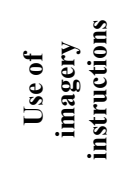 & 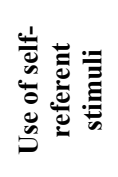 & 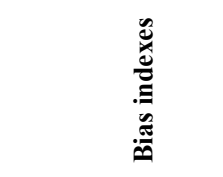 \\
\hline 37. Huppert et al., 2003 & 20.00 & 69.60 & Dimensional & UDS, ND & 102 & MIB & Direct & No & Yes & Absolute \\
\hline 38. Juang \& Knight, 2015 & 19.89 & 76 & Categorical & UDS, ND & 72 & AST & Direct & Yes & Yes & Relative \\
\hline 39. Käse et al., 2013 & 34.19 & 57.14 & Categorical & $\mathrm{CD}, \mathrm{ND}$ & 25 & $\begin{array}{l}\text { Affective startle } \\
\text { modulation }\end{array}$ & Indirect & Yes & No & Absolute negative \\
\hline 40. Kleim et al., 2014 & 24.44 & 58.33 & Dimensional & UDS, ND & 47 & AST & Direct & Yes & Yes & Relative \\
\hline 41. Krantz \& Hammen, 1979.1 & 18 & 57.49 & Categorical & $\mathrm{CD}, \mathrm{ND}$ & 212 & CBQ & Direct & Yes & No & Absolute negative \\
\hline 42. Krantz \& Hammen, 1979.2 & 18 & 57.49 & Categorical & $\mathrm{CD}, \mathrm{ND}$ & 314 & CBQ & Direct & Yes & No & Absolute negative \\
\hline 43. Lambert et al., 2013 & 33.00 & 100.00 & Dimensional & UDS, ND & 55 & BSIQ & Direct & No & Yes & Absolute negative \\
\hline 44. Lang et al., 2012 & 28.45 & 76.92 & Dimensional & $\mathrm{CD}$ & 26 & SST & Direct & No & Yes & Relative \\
\hline 45. Lawson \& MacLeod, 1999 & - & 62.50 & Categorical & UDS, ND & 32 & Semantic priming task & Indirect & No & No & Absolute negative \\
\hline 46. Lee et al., 2016 & 32.96 & 73.20 & Dimensional & $\mathrm{CD}, \mathrm{UDS}$ & 71 & $\begin{array}{l}\text { SST, facial emotional } \\
\text { identification task }\end{array}$ & $\begin{array}{l}\text { Direct, } \\
\text { Indirect }\end{array}$ & No & Yes, No & Absolute, Relative \\
\hline 47. Lievaart et al., 2013 & 41.69 & 63.88 & Dimensional & $\mathrm{CD}$ & 33 & Sentence completion task & Direct & No & Yes & Relative \\
\hline 48. Lo, 2009, u.p. & 24.98 & 45 & Categorical & $\mathrm{RD}, \mathrm{ND}$ & 40 & SST & Direct & No & Yes & Relative \\
\hline 49. Miller \& Norman, 1986.1 & 33.86 & 47.77 & Categorical & $\mathrm{CD}, \mathrm{ND}$ & 60 & CBQ & Direct & Yes & No & Absolute negative \\
\hline 50. Miller \& Norman, 1986.2 & 38.3 & 50.00 & Categorical & $\mathrm{CD}, \mathrm{ND}$ & 32 & CBQ & Direct & Yes & No & Absolute negative \\
\hline 51. Mobius et al., 2015.1 & 23.04 & 54.32 & Dimensional & UDS, ND & 81 & WSAP & $\begin{array}{l}\text { Direct, } \\
\text { Indirect }\end{array}$ & No & Yes & $\begin{array}{l}\text { Absolute positive, } \\
\text { Relative }\end{array}$ \\
\hline 52. Mobius et al., 2015.2 & 20.10 & 61.90 & Dimensional & UDS, ND & 105 & WSAP & $\begin{array}{l}\text { Direct, } \\
\text { Indirect }\end{array}$ & No & Yes & $\begin{array}{l}\text { Absolute positive, } \\
\text { Relative }\end{array}$ \\
\hline 53. Mogg et al., 2006 & 43.65 & 70.83 & Categorical & $\mathrm{CD}, \mathrm{ND}$ & 48 & $\begin{array}{l}\text { Homonym task, Semantic } \\
\text { priming task }\end{array}$ & $\begin{array}{l}\text { Direct, } \\
\text { Indirect }\end{array}$ & No & No & Absolute negative \\
\hline 54. Mor et al, 2014.1 & 25 & 55.10 & Dimensional & UDS, ND & 46 & Semantic priming task & Indirect & No & No & Relative \\
\hline 55. Mor et al, 2014.2 & 25 & 55.10 & Dimensional & UDS, ND & 28 & Semantic priming task & Indirect & No & No & $\begin{array}{l}\text { Absolute negative, } \\
\text { Absolute positive }\end{array}$ \\
\hline
\end{tabular}


Table 1. (continued).

\begin{tabular}{|c|c|c|c|c|c|c|c|c|c|c|}
\hline$\stackrel{\grave{E}}{E}$ & 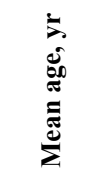 & 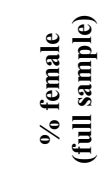 & 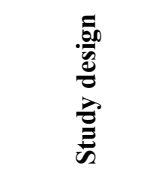 & 焉兽 & 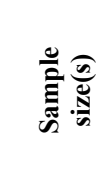 & 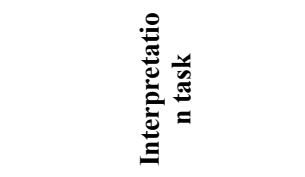 & 竞 & 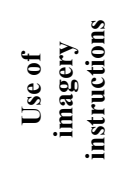 & 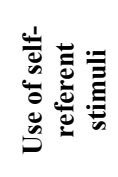 & 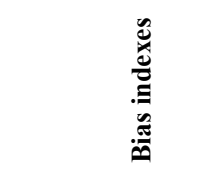 \\
\hline 56. Moser et al., 2012 & 24.97 & 71.42 & Categorical & $\mathrm{CD}, \mathrm{ND}$ & 29 & Semantic priming task & Indirect & No & Yes & $\begin{array}{l}\text { Absolute positive, } \\
\text { Absolute negative }\end{array}$ \\
\hline 57. Norman et al., 1983 & 37.8 & 53.33 & Dimensional & $\mathrm{CD}, \mathrm{ND}$ & 60 & CBQ & Direct & Yes & No & Absolute negative \\
\hline 58. Novović et al., 2014 & 19.59 & 62 & Dimensional & UDS, ND & 1071 & SST & Direct & No & Yes & Relative \\
\hline 59. Nunn et al., 1997 & 43.55 & 58.33 & Categorical & $\mathrm{CD}, \mathrm{ND}$ & 48 & IBQ & Direct & Yes & Yes & $\begin{array}{l}\text { Absolute positive, } \\
\text { Absolute negative }\end{array}$ \\
\hline 60. Phillips et al., 2012 & 29.91 & 81.37 & Dimensional & UDS, ND & 306 & SST & Direct & No & Yes & Relative \\
\hline 61. Pury, 2002 & - & 63.33 & Dimensional & UDS, ND & 29 & Homonym task & Direct & No & No & Relative \\
\hline 62. Rohrbacher \& Reinecke, 2014 & 24 & 77.27 & Dimensional & UDS, ND & 176 & AST & Direct & Yes & Yes & Relative \\
\hline 63. Rohrbacher et al., 2014 & 21.93 & 76.00 & Dimensional & UDS, ND & 54 & AST & Direct & Yes & Yes & Relative \\
\hline 64. Romero et al., 2014 & 21.87 & 80 & Categorical & $\mathrm{RD}, \mathrm{ND}$ & 70 & SST & Direct & No & Yes & Relative \\
\hline 65. Rude et al., 2001 & 34.16 & 75.60 & Categorical & $\mathrm{RD}, \mathrm{ND}$ & 41 & SST & Direct & No & Yes & $\begin{array}{l}\text { Absolute negative, } \\
\text { Absolute positive }\end{array}$ \\
\hline 66. Rude et al. 2002 & 18.34 & 74.63 & Dimensional & UDS, ND & 339 & SST & Direct & No & Yes & Relative \\
\hline 67. Rude et al. 2003 & 18.1 & 80.95 & $\begin{array}{l}\text { Categorical } \\
\text { Dimensional }\end{array}$ & $\mathrm{CD}, \mathrm{ND}$ & 84 & SST & Direct & No & Yes & Relative \\
\hline 68. Rude et al., 2010 & 35.23 & 100.00 & Dimensional & $\mathrm{RD}, \mathrm{ND}$ & 43 & SST & Direct & No & Yes & Relative \\
\hline 69. Sanchez et al., 2015 & - & 75.00 & Dimensional & UDS, ND & 52 & SST & Direct & No & Yes & Relative \\
\hline 70. Sanchez et al., 2016 & 22.20 & 83.33 & Dimensional & UDS, ND & 38 & SST & Direct & No & Yes & Relative \\
\hline 71. Sears et al., 2011 & 20.80 & 100.00 & Categorical & UDS, ND & 82 & WSAP & $\begin{array}{l}\text { Direct, } \\
\text { Indirect }\end{array}$ & No & Yes & $\begin{array}{l}\text { Absolute positive, } \\
\text { Absolute negative }\end{array}$ \\
\hline 72. Seeds 2012 u.p. & 18.57 & 100.00 & Dimensional & UDS, ND & 184 & $\begin{array}{l}\text { SST, Semantic priming } \\
\text { task }\end{array}$ & $\begin{array}{l}\text { Direct, } \\
\text { Indirect }\end{array}$ & No & Yes & $\begin{array}{l}\text { Absolute positive, } \\
\text { Absolute negative, } \\
\text { Relative }\end{array}$ \\
\hline 73. Starr \& Moulds, 2006 & 19.38 & 73.80 & Dimensional & UDS, ND & 68 & RIQ & Direct & No & Yes & Absolute negative \\
\hline 74. Teasdale et al., 1995 & 40.2 & 67.70 & Categorical & $\mathrm{CD}, \mathrm{ND}$ & 81 & Sentence completion task & Direct & No & Yes & Relative \\
\hline 75. Teasdale et al., 1998 & 44.6 & 69.65 & Categorical & UDS, ND & 145 & Sentence completion task & Direct & No & Yes & Relative \\
\hline
\end{tabular}




\begin{tabular}{|c|c|c|c|c|c|c|c|c|c|c|}
\hline 总 & 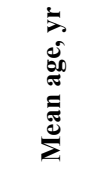 & 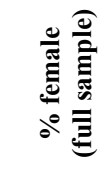 & 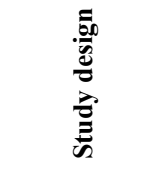 & 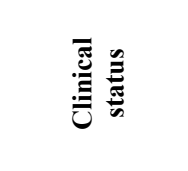 & 递 & 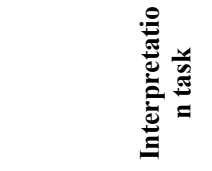 & 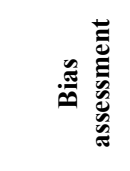 & 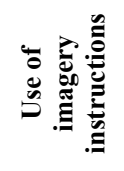 & 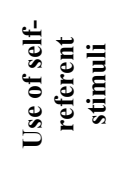 & 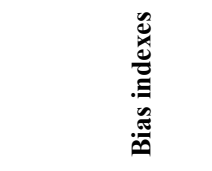 \\
\hline 76. Torkan et al., 2014 & 27.61 & 64.10 & Dimensional & $\mathrm{CD}$ & 39 & SST & Direct & No & Yes & Relative \\
\hline 77. Van Der Does, 2005 & 26.40 & 70.83 & Categorical & $\mathrm{RD}, \mathrm{ND}$ & 48 & SST & Direct & No & Yes & Relative \\
\hline 78. Voncken et al., 2007 & 39.00 & 57.20 & Categorical & $\mathrm{CD}, \mathrm{ND}$ & 55 & IJQ & Direct & Yes & Yes & Relative \\
\hline 79. Watkins \& Moulds, 2007 & 37.68 & 55.00 & Categorical & $\mathrm{CD}, \mathrm{RD}, \mathrm{ND}$ & 30 & SST & Direct & No & Yes & Relative \\
\hline 80. Wenzlaff \& Bates, 1998 & 19.70 & 65.55 & Categorical & UDS, CD, ND & 90 & SST & Direct & No & Yes & Relative \\
\hline 81. Wenzlaff \& Eysenberg, 2001 & 19.74 & - & Categorical & $\mathrm{CD}, \mathrm{RD}, \mathrm{ND}$ & 87 & Homonym task & Direct & No & No & $\begin{array}{l}\text { Absolute positive, } \\
\text { Absolute negative }\end{array}$ \\
\hline 82. Williams et al., 2013 & 44.81 & 76.19 & Dimensional & $\mathrm{CD}$ & 63 & SST, AST & Direct & No, Yes & Yes & Relative \\
\hline 83. Williams et al., 2015 & 41.90 & 69.00 & Dimensional & $\mathrm{CD}$ & 75 & AST & Direct & Yes & Yes & Relative \\
\hline $\begin{array}{l}\text { 84. Wisco \& Nolen-Hoeksema, } \\
2010.1\end{array}$ & 21.40 & 62.20 & Categorical & UDS, ND & 98 & IBQ & Direct & Yes & No, Yes & Relative \\
\hline $\begin{array}{l}\text { 85. Wisco \& Nolen-Hoeksema, } \\
2010.2\end{array}$ & 19.85 & 60.40 & Categorical & UDS, ND & 96 & IBQ & Direct & Yes & No, Yes & Relative \\
\hline 86. Wisco \& Nolen-Hoeksema, 2011 & 21.80 & 61.30 & Categorical & UDS, ND & 110 & IBQ & Direct & Yes & Yes & Relative \\
\hline 87. Yiend et al. 2013 & 43.12 & 72.22 & Dimensional & $\mathrm{CD}$ & 36 & SST & Direct & No & Yes & $\begin{array}{l}\text { Absolute positive, } \\
\text { Absolute negative }\end{array}$ \\
\hline
\end{tabular}

Notes. u.p. $=$ unpublished paper; UDS $=$ undiagnosed elevated depressive symptoms; $\mathrm{CD}=$ clinical depression; $\mathrm{RD}=$ remitted depressed; $\mathrm{ND}=$ non-depressed; $\mathrm{AST}=\mathrm{Ambiguous} \mathrm{Scenarios} / \mathrm{Story}$ completion Test; IEM = Interpretation of Events Measure; ASSIQ = Ambiguous Social Scenario Interpretation Questionnaire; AUSD = Ambiguous/Unambiguous Situations Diary; BSIQ = Bodily Sensations Interpretation Questionnaire; $\mathrm{CBQ}=$ Cognitive Bias Questionnaire; IEM = Interpretation of Events Measure (Dohr, 1987); IQSD = Interpretation Questionnaire for Social Phobia and Depression; MIB = Measure of Interpretation Bias; SCT = Sentence Completion Task; SST = Scrambled Sentence Test; RIT = Recognition of Information Task; WSAP = Word Sentence Association Paradigm; RIQ = Response to Intrusions Questionnaire; IBQ = Interpretation Bias Questionnaire; IJQ = The Interpretation and Judgmental Questionnaire; IQSD = Interpretation Questionnaire for Social Phobia and Depression. 
Table 2. Ratings for the adapted 'Checklist for Measuring Quality'.

\begin{tabular}{llcc}
\hline Item & & $M$ & $S D$ \\
\hline 1 & Study hypothesis/aim/objective described? & 1.00 & 0.00 \\
2 & Main outcomes described in the introduction or methods? & 0.97 & 0.16 \\
3 & Participant characteristics described? & 0.92 & 0.27 \\
4 & Contacted participants representative? & 0.87 & 0.33 \\
5 & Prepared participants representative? & 0.86 & 0.35 \\
6 & Participants recruited from the same population? & 0.70 & 0.46 \\
7 & Participants recruited over the same time? & 0.97 & 0.16 \\
8 & Measures and experimental tasks described? & 1.00 & 0.00 \\
9 & Main outcome measures valid and reliable? & 1.00 & 0.00 \\
10 & Task engagement assessed? & 0.33 & 0.50 \\
11 & Confounders described and controlled for? & 1.01 & 0.65 \\
12 & Statistical tests appropriate? & 1.00 & 0.00 \\
13 & Main findings described? & 0.97 & 0.16 \\
14 & Estimates of the random variability in data main outcomes? & 0.86 & 0.35 \\
15 & Probability values reported? & 0.58 & 0.50 \\
16 & Withdrawals and drop-outs reported? & 0.61 & 0.49 \\
17 & Data dredging made clear? & Sufficient power analysis provided? & 0.27 \\
\hline
\end{tabular}

Notes. All items have a maximum score of 1.00 except item 11 has maximum score of 2.00; Appendix S1 provides a full description of the individual items. 
Table 3. Results overall effect size and moderators.

\begin{tabular}{|c|c|c|c|c|c|c|c|}
\hline & & $\mathbf{N}_{\text {comp }}$ & $\mathbf{g}$ & g 95\%-CI & $\mathbf{I}^{2}$ & $\mathrm{I}^{2} 95 \%$-CI & $\mathbf{p}$ \\
\hline \multicolumn{8}{|l|}{ Overall effect size } \\
\hline \multicolumn{2}{|l|}{ All studies } & 87 & 0.72 & $0.62 ; 0.82$ & 75 & $69 ; 79$ & $<0.001$ \\
\hline \multicolumn{2}{|l|}{ Outliers excluded ${ }^{\mathbf{a}}$} & 74 & 0.74 & $0.66 ; 0.82$ & 50 & $34 ; 62$ & $<0.001$ \\
\hline \multicolumn{8}{|l|}{ Moderators } \\
\hline \multirow[t]{3}{*}{ Clinical status of depression } & $\begin{array}{l}\text { Undiagnosed elevated } \\
\text { depressive symptoms }\end{array}$ & 21 & 0.66 & $0.47 ; 0.84$ & 73 & $58 ; 82$ & \multirow{3}{*}{0.768} \\
\hline & Clinical depression & 21 & 0.60 & $0.37 ; 0.75$ & 68 & $50 ; 80$ & \\
\hline & Remitted depression & 9 & 0.59 & $0.33 ; 0.86$ & 37 & $0 ; 71$ & \\
\hline \multirow[t]{2}{*}{ Self-referent stimuli } & No & 30 & 0.37 & $0.23 ; 0.52$ & 67 & $52 ; 77$ & \multirow[t]{2}{*}{$<0.001$} \\
\hline & Yes & 62 & 0.90 & $0.78 ; 1.01$ & 72 & $65 ; 79$ & \\
\hline \multirow[t]{2}{*}{ Mental imagery instructions } & No & 61 & 0.72 & $0.58 ; 0.85$ & 79 & $73 ; 83$ & \multirow[t]{2}{*}{0.787} \\
\hline & Yes & 29 & 0.74 & $0.59 ; 0.90$ & 75 & $64 ; 82$ & \\
\hline \multirow[t]{2}{*}{ Measurement method } & Direct & 76 & 0.88 & $0.77 ; 0.99$ & 77 & $71 ; 81$ & \multirow{2}{*}{$<0.001$} \\
\hline & Indirect & 20 & 0.04 & $-0.14 ; 0.22$ & 59 & $34 ; 75$ & \\
\hline \multirow[t]{3}{*}{ Interpretation bias scores } & Absolute positive & 22 & 0.60 & $0.36 ; 0.85$ & 84 & $76 ; 89$ & \multirow{3}{*}{0.043} \\
\hline & Absolute negative & 43 & 0.58 & $0.40 ; 0.75$ & 80 & $74 ; 85$ & \\
\hline & Relative & 44 & 0.85 & $0.70 ; 1.00$ & 81 & $75 ; 86$ & \\
\hline \multirow[t]{2}{*}{ Study design ${ }^{b}$} & Dimensional & 41 & 0.86 & $0.73 ; 0.99$ & 73 & $63 ; 80$ & \multirow[t]{2}{*}{0.004} \\
\hline & Categorical & 46 & 0.59 & $0.46 ; 0.71$ & 67 & $55 ; 76$ & \\
\hline
\end{tabular}

Notes. $\mathrm{N}_{\text {comp }}=$ number of comparisons; The p-values in the last column indicate whether the difference between the ESs of the levels of the moderator

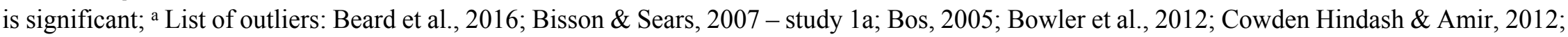
D'Avanzato, 2013; Everaert et al., 2014; Goggin et al., 2011; Krantz \& Hammen, 1979.1; Lawson \& MacLeod, 1999; Mobius et al., 2015, study 1; Novovic et al., 2014; Phillips et al., 2012; b Though this moderator was significant, sensitivity analyses produced no significant differences between moderators for categorical and dimensional studies. 


\section{Author biography}

Jonas Everaert is a postdoctoral research fellow at Yale University, USA.

Ioana R. Podina is an assistant professor at the University of Bucharest, Romania.

Ernst H.W. Koster is an associate professor at Ghent University, Belgium. 


\section{Author disclosure}

\section{Role of funding sources}

This research was supported by a grant from the Belgian American Educational Foundation awarded to Jonas Everaert, and the Romanian National Authority for Scientific Research and Innovation (CNCS-UEFISCDI, PN II-RU-TE-2014-4-2481, 293/01/10/2015) awarded to Ioana R. Podina.

\section{Contributors}

JE, IRP, and EHWK designed the study and wrote the meta-analytic protocol. JE and IRP conducted literature searches, provided summaries of previous research, and coded the study characteristics under supervision of EHWK. IRP conducted the analyses in consultation with JE and EHWK. JE wrote the first draft of the manuscript and critical feedback was provided by IRP and EHWK. All authors have approved the final manuscript.

\section{Conflict of interest}

All authors declare that they have no conflicts of interest.

\section{Acknowledgements}

The authors thank Jan De Houwer and Alishia D. Williams for their thoughtful comments on earlier drafts of this manuscript. The authors thank Mirela Mohan for the language proofing and Nolan Sheridan for his assistance with the literature search. 